$B 655$ 0 5B 13356

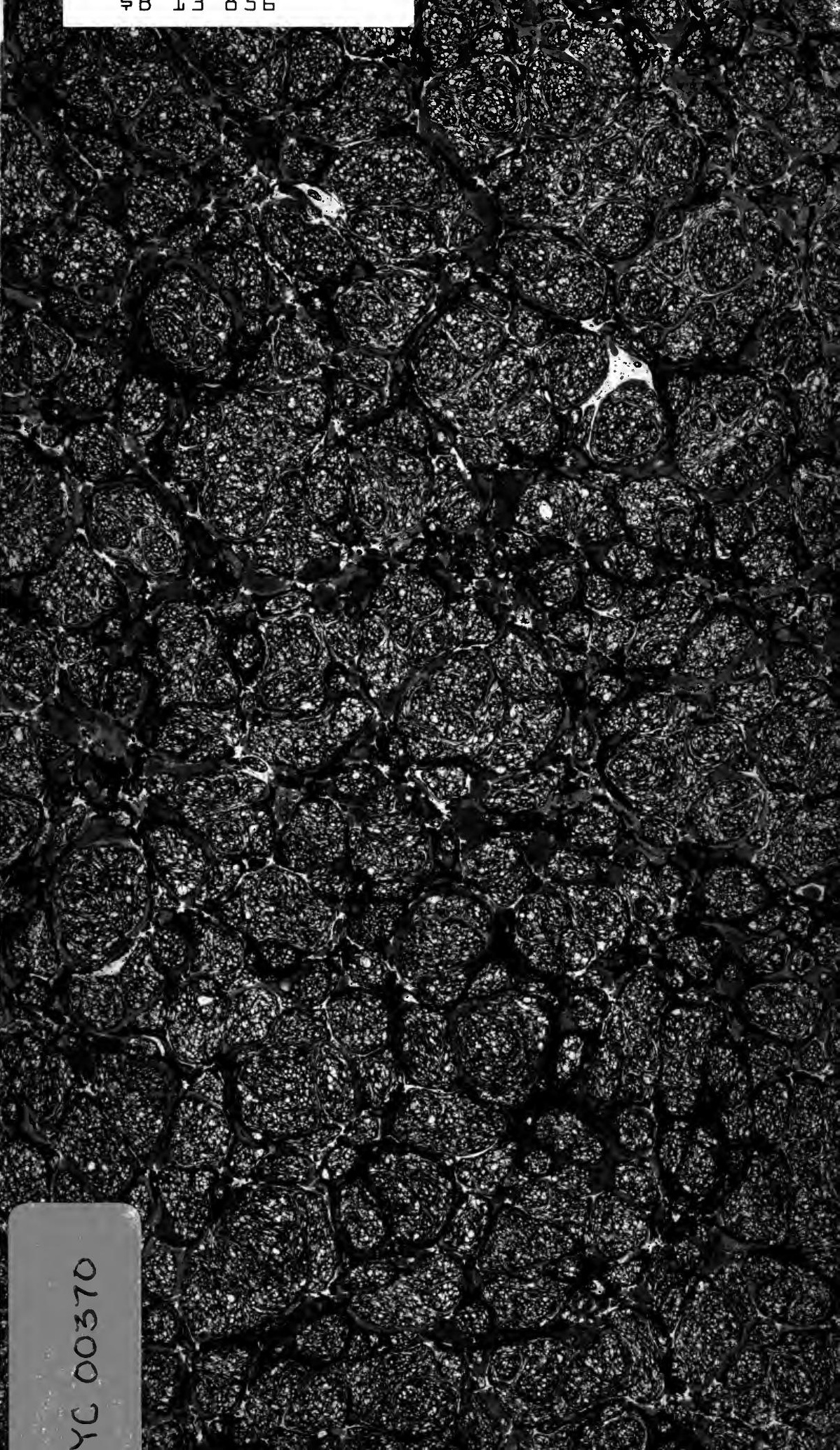




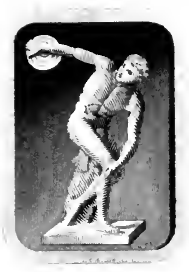

Titratry nf

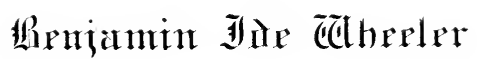



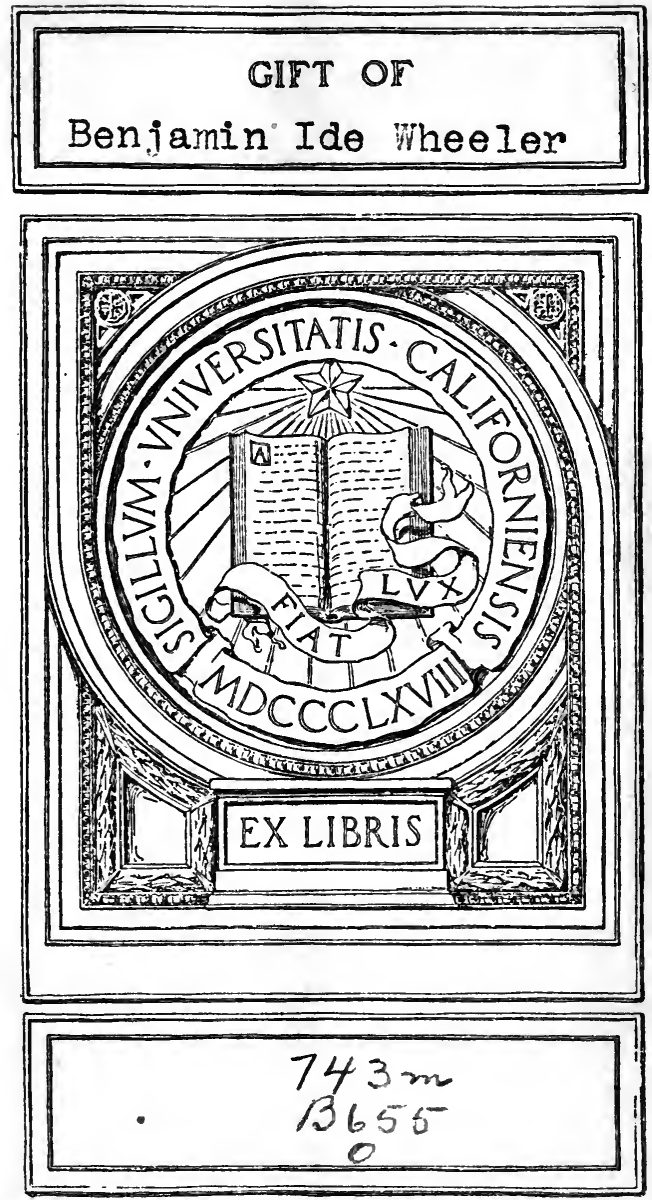


\section{The Origin of the Recessive Accent in Greek.}

BY

MAURICE BLOOMFIELD

JOHNS HOPKINS UNIVERSITY

Reprinted from The American Journal of Philology, Vol. IX, Nc. T, pp. I-4I.

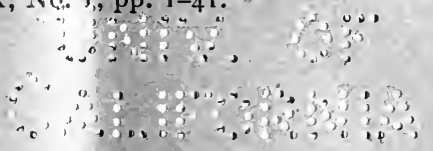

B A L T I M OR E, I 888

Publication Agency of the Johns Iopkins University 


\section{$a^{76}$}

\section{THE ORIGIN OF THE RECESSIVE ACCENT IN GREEK.}

Jacob Wackernagel, in KZ. XXIII 457 fg., made the important discovery that the so-called 'recessive' accent in the finite forms of the Greek verb represents a substitute for an older IndoEuropean fact in sentence-accentuation, to wit, that the finite verb in principal clauses was treated as an enclitic. This enclisis was extended in Greek to the finite verb in both principal and subordinate clauses, but was, on the other hand, restricted by a law according to which an enclitic word may not contain more than two syllables and three moras. Therefore only two syllables at the end are allowed to be barytone: $\phi \epsilon \rho^{\prime} \rho \mu \epsilon \nu$ for enclitic ${ }^{*}{ }_{\phi \epsilon \rho o \mu \epsilon \nu}$; three moras at the utmost, and that only in a polysyllabic form,

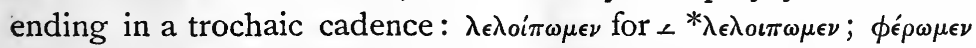
for $\_{ }^{*} \phi \epsilon \omega \mu \epsilon \nu$. Elsewhere only two moras were left barytone:

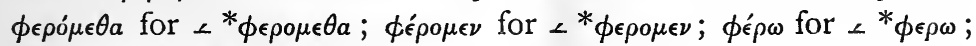

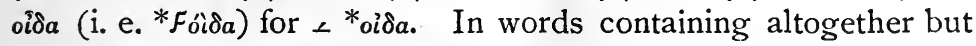
two moras, one was left barytone: $\lambda i \pi \epsilon s$, augmentless aorist for $\left\llcorner{ }^{*} \lambda_{\imath \pi \epsilon s} ; \beta \hat{\eta}\right.$ (i. e. $\left.{ }^{*} \beta \epsilon_{\epsilon}^{\prime}\right)$, augmentless aorist for $\angle{ }^{*} \beta \eta$. Monosyllabic forms of one mora are accented, so that no mora is left toneless: $\beta a ́ \nu, \sigma \tau a ́ \nu, \phi \theta a ́ \nu$, augmentless aorists for $\angle *_{\beta}^{*} \breve{a} \nu$, etc.

We may refrain at present from any attempt at justifying the derivation of these 'recessively' accented verbal types from the assumed enclisis : we shall return to that question in the end. It is enough to state that these accentual types are one and all derivable from the enclitic theory, and that they represent every conceivable manifestation of the 'recessive' mode of accentuation, providing only it is remembered that words of more than three 
syllables are treated in the same way as words of three syllables: $\delta o \theta \eta \sigma o ́ \mu \epsilon \theta a$, $\delta v \nu a ́ \mu \epsilon \theta a$ like $\eta \tilde{\mu} \epsilon \theta a$, etc.

In an article entitled 'Historical and critical remarks introductory to a comparative study of Greek accentuation,' American Journal of Philology, IV 2I fg., I proposed an extension of this law, so that it would serve as a theory by which all non-etymological accentuation in Greek words could be accounted for. My statements were as follows:

P. 56 (p. 36 of the reprint). 'The explanation of the Greek recessive accent must start from the finite form of the verb, where alone it is evidently at home.'

P. 30 (IO). 'It is a fact perfectly clear that the recessive accent in Greek, whatever its explanation, started with the finite forms of the verb, and thence succeeded in attacking nominal formations also.'

P. 50 (30). 'It (the recessive accent) excludes with particular care non-finite forms of the verb in the same tense system and in evident connection with finite forms, exhibiting thus on Greek ground a most outspoken character as a grammatical quality of finite verbs.'

P. 62 (42). 'No doubt the noun has to a large extent followed the verb in its enclisis.'

This theory involves, of course, the belief that the extension of the recessive accent from the verb to the noun took place according to processes of analogy, not different in principle from those which elsewhere break in upon the regular line of phonetic facts. I shall show below, in a somewhat detailed fashion, the manner in which this must be imagined to have taken place.

The only writer, since the publication of my treatise, who has subjected the question of the recessive accentuation in Greek to an independent investigation is B. I. Wheeler, in his book, Der Griechische Nominalaccent, Strassburg, 1885. Wheeler's work has been for me, as for others, one of great interest. He has brought to his work good training and esprit. His method of investigation is comprehensive; he does not draw an arbitrary line which cuts off the domain of his inquiry from adjoining territory open to search and likely, nay certain, to yield information. His study is nothing if not comparative. His methods are rigorously exact, perhaps a little overdrawn in that direction, as I shall endeavor to show in the sequel. He seizes upon, with rather too eager emphasis, the working principle which I formulated in my article, p. 3I (II) 
fg., namely, that accent must be investigated with the same fundamental presumptions, or principles, as other phonetic matter. Phonetic change in accordance with phonetic law and analogy, I urged, loc. cit., are the prominent factors, aside from the influence of foreign words, which are at the bottom of the frequently portentous changes on the face of the accentuation of a given language. Wheeler operates with these factors almost entirely, but he narrows the operation of both so as to admit under these heads only such phenomena of change as appear familiarly in extra-accentual phonetics. He fails to do justice to the fact that the centrifugal force of phonetic change and the centripetal force of analogy operate both at a totally different rate in the change of accentuation, and in the change of other phonetic material, simply because the scope of any accentual type is greater than that of any type involving a given mode of vocalization or consonantal treatment. The application of the principles of phonetic law and analogy to the accentuation of the Lettish dialect is a la rigueur justifiable, but it must be done in the spirit of the preceding sentence. The Lithuanian is related so closely to Lettish that the two are preponderatingly convertible, if a certain number of phonetic changes are rigorously observed. The Lithuanian exhibits a free accentuation which can be compared and identified with the Vedic accent in spite of many deviations. The Lettish, which is related as closely to the Lithuanian as the language of Herodotus is to that of Thucydides, has abrogated all etymological accentuation and has the summit tone everywhere on the first syllable. The change from the free Baltic accentuation as represented by the Lithuanian to this mechanical accentuation' of the Lettish is due, or may be due, to a preponderance of the analogy of such words as accented the first syllable etymologically, and in this sense the change is analogical. But it would be useless to demand further that every word which obtained this accentuation secondarily must exhibit some formal or functional cause for adopting it. Only in this sense can a levelling accentuation be the result of analogy. Such are the accentuation of the radical syllable in German, the accentuation of the final syllable in the French of the last century, the accentuation of the first syllable in Bohemian and Sorbian, the accentuation of the penult in Polish and Welsh, the complete 'recessive' accentuation of the Aeolic, the practically complete barytonesis of Latin and its restriction of the accent within three syllables, etc. Analogy with its ordinary scope-word influencing word, form 
influencing form-may carry on its humble working by the side of and in the teeth of a great leveling tendency. '́xvpós 'father-inlaw' may exhibit oxy tone accentuation secondarily after the analogy of '́xvpá in spite of the 'recessive' tendency (Wheeler, p. 59). Originally it was *ěkvpos; cf. Sk. çváçura-; Gothic swaih ra (orig. Ger-

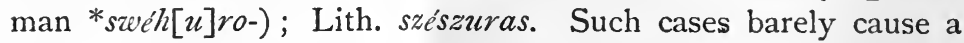
ripple on the quiet, strong current which carries the accentuation into the opposite direction.

The foundation upon which Wheeler's book is built is a new theory in explanation of the 'recessive' accentuation. He denies that the phenomena thus designated were originally a property of the finite verb, and claims that they are due to a phonetic fact which permeated the whole material of the language. He follows a suggestion of Osthoff's, which had been previously indicated by Curtius, and assumes that in words containing a sufficient number of moras a secondary accent was developed, which fell upon the third mora from the end in all words except those of more than two syllables ending in a trochee; in the latter the secondary accent fell upon the fourth mora from the end. ${ }^{1}$ This secondary accent is assumed to have developed upon all spondaic and iambic words and upon all words of three or more syllables. For reasons which it puzzles the reader to find out, he excludes from the effect of this secondary accent trochaic dissyllables (oînos 'way' =Sk. éma-; Fєỉos 'appearance' $=\mathrm{Sk}$. védas ; aîtos 'fire' $=\mathrm{Sk}$. édhas), though

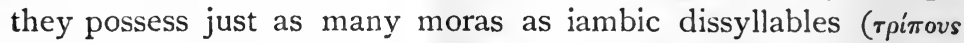
'tripod' $=$ Sk. tripá $d$ ), and the 'secondary' accent is palpably represented by the circumflex. About this more below.

From the benefits of this 'secondary' accentuation he therefore excludes short monosyllables, long monosyllables, words of two short monosyllables, and trochaic dissyllables. He assumes, moreover, that this secondary accentuation gained the upper hand under certain circumstances, while under others the old etymological accent survived. Accordingly he divides the whole material of the language into four categories, barring of course the special effects of other minor phonetic laws and analogies, ${ }^{2}$ as follows:

${ }^{1}$ Cf. Curtius in Fleckeisen's Jahrbücher for 1855, p. 342 ; Osthoff, cited by Wheeler, p. Io, note 2 ; and Wheeler, p. 9 fg.

${ }^{2}$ Wheeler in reality posits five divisions, but his fourth division is one altogether independent of the general theory. In it he has collected considerable material which aims towards the establishment of a phonetic law previously hinted at by Bopp and Curtius, according to which words originally oxytone, 
I. Monosyllabic forms and dissyllabic ones with short final syllable retain the inherited accent intact.

II. If the original accent lay nearer to the beginning of the word than the secondary accent, then the secondary accent prevailed.

III. If the original accent coincides with the secondary accent, then it remains undisturbed.

IV (Wheeler's No. V). If the original accent lay nearer to the end of the word than the secondary accent, there arose a vacillation which was settled later on in favor of one or the other. Sometimes the cause of the choice is apparent, sometimes not.

Wheeler's book was reviewed by Wackernagel in the Deutsche Literaturzeitung for I886, column 221 fg. (No. 7); by Delbrück in the Literarisches Centralblatt for I886, column 290 (No. 9); by Fr. Stolz in the Neue Philologische Rundschau for I886, column I37 fg. (No. 9); by Walter Prellwitz in the Göttinger Gelehrte Anzeigen for I886, p. 755 fg. (No. 19 of September 15); by Kautzmann in the Berliner Philologische Wochenschrift for I886, column 597 fg. (No. 19); by Peile in the Classical Review for I887, Vol. I, No. 4, p. 103 fg.; finally by a writer in The Nation (New York) for 1886, April 8 (No. 1084, p. 304). Moreover, Brugmann has carried this theory bodily into his treatment of Greek accent in his Grundriss der Vergleichenden Grammatik; Vol. I, p. 543 fg.

There are in the list just mentioned as fair scholarly names as can be mustered from the ranks of the workers in Indo-European philology, and yet I venture to say that Wheeler's book has hitherto not been subjected to the kind of criticism which it deserves. The glamour of his attractive method and the many excellent observations in detail have blinded his readers to the fundamental errors upon which his book is built.

In the following I shall endeavor to show that his theory is untenable on account of the following misconceptions :

I. He regards the recessive accent as one which manifests itself only on the penult or antepenult, only on the third or fourth mora from the end, and fails to recognize the fact that dissyllabic words of two moras ( $\lambda i \pi \epsilon s$ above), and monosyllabic words can also be

having a dactylic final cadence, become paroxytones in Greek. To a criticism of this thesis we may hope to return at some future time. This is the fourth of Wheeler's five theses, and as we shall not be concerned with it we will omit it in the count. 
accented, either etymologically or recessively, precisely as dissyllabic or polysyllabic words of three or more moras.

2. He fails to recognize the fact that barytone dissyllabic trochaic words are, with a regularity which knows practically no exception, accented recessively, not etymologically. ${ }^{1}$

1A 3. Throughout the treatise the difference between circumflex and acute accent is practically ignored, while in reality a circumflex upon the same syllable as an acute indicates in the vast majority of cases not only a difference in the quality of the tone, but also a difference of position. The circumflex accent marks an accentuation further away from the end of the word than the acute.

4. He has obliterated the difference which is manifestly exhibited in the scope of the recessive accent in the domain of the finite verb on the one hand, and of the remaining word-forms on the other.

5. Wheeler was led to his identification of the recessive accent with a secondary accent by a fact hinted at by Wackernagel and expanded in my article, p. 43 (23). My statement is: 'Enclisis and recessive accent are ruled by the same law of three morae.' . . .

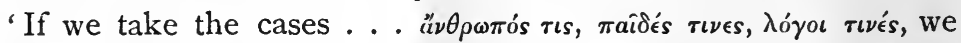
have in every case an enclisis which is rectified or rather cut short by the law of three morae as exhibited in the general recessive accent.' The identification of the recessive accent of the verb with the secondary accent of a group consisting of an orthotone word plus an enclitic word is the keynote of Wackernagel's and my own theory. In the group « goes hand in hand with the existence of a second word; the enclitic

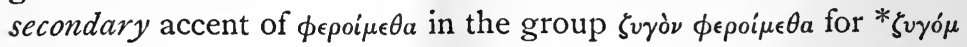

${ }^{1}$ The $\pi \rho \tilde{\omega}$ Tov $\psi \varepsilon \tilde{v} \delta \rho \varsigma$ which vitiates Wheeler's theory manifests itself very clearly in his statement on p. 2: "Den 'recessiven" accent müssen wir also so aufnehmen wie wir ihn vorfinden: als einen accent, der auf der antepaenultima oder paenultima ruht, je nachdem ob die endsilbe kurz oder lang ist." This statement shows, as does the entire treatise, that the 'recessive' character of the following accentual types has in reality escaped his notice: (I) oi $\delta a(\Sigma \cup)$;

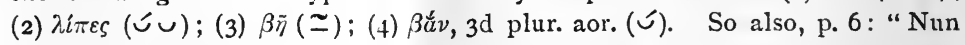
ist aber der recessive accent kein specifischer accent, sondern vielmehr ein accentprinzip, und fasst in sich paroxytona, proparoxytona, und properispomena." This is true, but it embraces, furthermore, perispomena, and short monosyllabic oxytona. The two statements are, moreover, inconsistent: the properispomena which are introduced as 'recessive' on p. 6 are excluded by the statement on p. 2, as also impliedly on p. ro: "Ich gehe so weit und nehme diesen nebenton für jedes spondäische, iambische oder polysyllabische wort an." 
$\phi \epsilon \rho \circ \mu \in \theta a$ (=I. E. yugóm bheroimedha) is also due to the second word. Wheeler, in claiming that a single word in sentence-nexus, e. g. * ${ }^{\prime}{ }^{\prime} \nu \rho \mu \epsilon \nu o s=S k . ~ j a n a m a \bar{n} a s$, developed the same secondary accent, demonstrably associated only with presence of a second word, advances a hypothesis which is unlikely on the face of it, and whose untenableness will be demonstrated in the course of this essay.

We turn now to a review of the several theses. propounded by Wheeler and reported above.

On pages $13-38$ he attempts to prove his first thesis, namely, that monosyllabic words and dissyllabic words with short final syllables retain the original etymological accentuation intact. As far as long monosyllables are concerned this statement is correct in the equation $z \epsilon^{\prime} s=\mathrm{Sk}$. dyāuis $=\mathrm{I}$. E. diêtus, but it is incorrect in the equations $\nu a \hat{s}=\mathrm{Sk} . n \bar{a} u \dot{s}=\mathrm{I}$. E. $\dot{n} \bar{a} u s ; \mu \hat{v} s=\mathrm{Sk} \cdot m \dot{u} \underline{u}=$

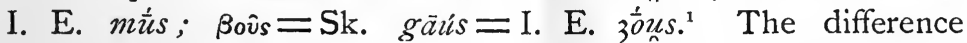
between the accentuation of vavis and $\mathrm{Z} \in \dot{w}$ s, as far as quality and position are concerned, is clearly the same as that in $\beta \hat{\eta} \nu$ Il. I3. $297, \beta \hat{\omega}$ Eur. Alc. 864 , when compared with $\beta a^{\prime} s$ Il. $6.65 ; \AA$ (from

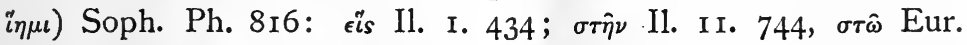
Alc. 864: $\sigma \tau^{a ́ s}$ I1. 16. 231 ; $\theta \hat{\omega}$ Soph. O. C. $480: \theta$ tis Il. 23. 254;

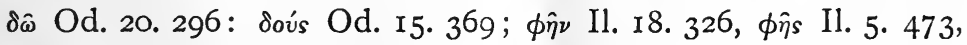
$\phi \hat{\eta}$ Il. 2. 37, $\phi \hat{a}$ Pind. I 2. II, $\phi \hat{\omega}$ Aesch. Ch. $9 \mathrm{I}: \phi \bar{a} s$ Il. 9. $35 ; \delta \hat{v}$

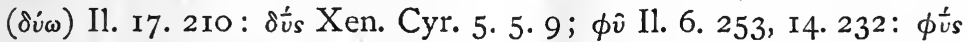
Od. 18. 4 IO, Pind. Ol. II. 20 ; $\gamma \nu \hat{\omega} \nu$ Il. 4. 357, Hes. Th. 551. 3,

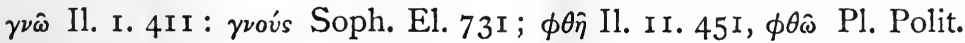

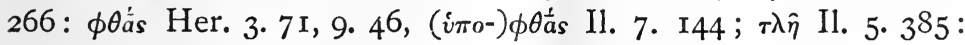

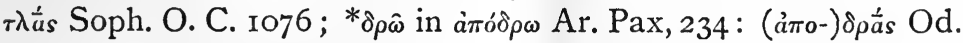
17. 516; ${ }^{2} \nu$, 'I was,' Il. 2. 95, Soph. Tr. 414, etc. (see Veitch, Greek Verbs Irregular and Defective, I879, p. 225), i $s$ ' he was,' Doric e. g. IA. 342. 3, Lesbian, Theocr. 3o. I6, Tegeatic, (Gelbke in Curtius' Studien II 40; G. Meyer, Griech. Gramm. ${ }^{2}$ p. 432), iv, 'he was,' Il. 5. 9, Soph. Tr. 9, Thuc. 2. 3, etc. (Veitch, ibid.): $\ddot{\omega} \nu$ Hom. Hymns 19. 32, Soph. Ag. 767, etc., Æ's Doric, Lesbic (KZ. XXVII 393). We may add the circum-

${ }^{1}$ I shall endeavor to show below (p. 18) that the equations $\beta \tilde{\omega} \nu=$ Vedic

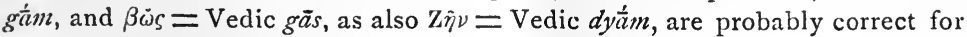
accent as well as the sounds.

${ }^{2} \dot{\eta}$ 'I was,' Aesch. Ag. I637, Soph. O. C. 973, etc. (Veitch, p. 225), is Attic contraction of the old perfect-form $\tilde{\eta} a=\mathrm{Sk} . \grave{a} s a=\mathrm{I}$. E. $\stackrel{\dot{e}}{\mathrm{e}} \mathrm{sm}$. The subjunctive Attic $\dot{\omega}$ is also a contract form from Epic $\check{\varepsilon} \omega$. 
flected monosyllables: $\eta$, 'he said,' Il. 6. 390, 22. 77, Od. 3. 337, 22. 292, Theocr. 22. 75, Plato Rep. 327 ; $\eta^{2}$, 'I said,' Pl. Rep. 328, Luc. Philop. 23. Here also perhaps belongs $\kappa \nu \eta$ ' he scraped,' Il. II. 639: see Veitch, 379; G. Meyer ${ }^{2}$, p. 47. The accent of the augmentless imperfect $\chi \rho \hat{\eta} \nu$, Pind. Fr. 100, Soph. El. 529, 579, etc. (Veitch, p. 707), can be considered significant only in so far as it may perhaps reflect the accent of $\eta^{\nu} \nu$ ( $\chi \eta^{\prime}$ plus $\left.{ }^{\eta} \nu\right)$; cf. G. Meyer ${ }^{2}$, p. 430, note 2. Further instances of long monosyllabic oxytone

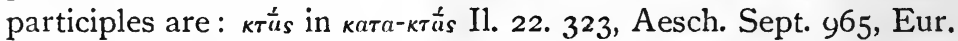

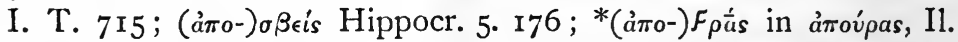

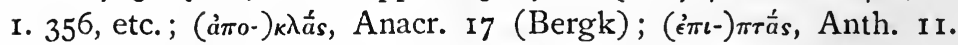

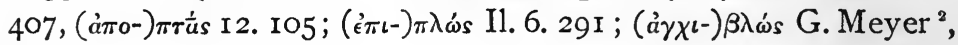
p. 459 .

No one can fail to admit that the difference between the oxytone accentuation of these long monosyllabic participles and the perispomenon of the finite forms is fundamental: that in fact the accent of the participles is etymological, and that of the finite forms is recessive. As $\beta \hat{\eta}{ }^{1}{ }^{1}$ is to $\beta^{\frac{1}{u} s}$, so are $\lambda_{i \pi \epsilon s}$ Il. Io. $406: \lambda_{\imath} t \dot{\omega} \nu$ Il. 9.

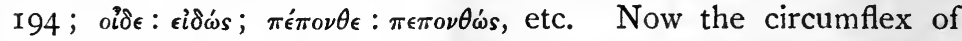
vav̀s, $\mu \hat{v} s, \beta o \hat{v} s, \beta \hat{\omega} s$, as well as the circumflex of Aeolic $Z \in \hat{v} s, \pi \tau \hat{\omega} \xi$, etc., differs from the acute of Zeús in the same way: it is recessive.

The same difference is to be found in a considerable number of nominatives, consisting of a long monosyllable, for which no etymology, or only a partial one has been found. ${ }^{2}$ The following are oxytone, and have presumably preserved the old accentuation of this type. In a number of cases there is a conflict of authorities, which is indicated under the word discussed:

$\mu \eta \nu^{\prime}$ 'month,' Doric $\mu \eta_{s}$, Ionic $\mu \epsilon^{\prime}{ }^{3}{ }^{3}$ : I. E. stems mēns-, mēs-, Vedic mǻs (? män ç-catí, Grassm.); Lat. mèns-is, Goth. mēna, Lith. ménů, Old Irish mí, Old Bulg. měseci.

$\chi \theta \dot{\omega} \nu$ ' earth': Vedic stem kṣam-, Zend zem-, Lat. hum-us, Lith. ž́me, Old Bulg. zemlja.

$\chi \dot{\eta} \nu$ 'goose': Doric $\chi^{\frac{1}{a} \nu}$ : Sk. hañsá, Lat. anser, OHG. gans, Lith. žasis, Old Bulg. gaš̆.

$\chi \eta_{\rho} \rho$ 'hedgehog' (Hesych.): Lat. hèr; cf. Cu. Etym. ${ }^{5}$, p. 200.

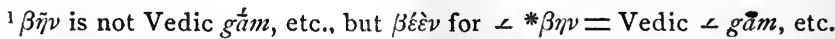

${ }^{2}$ It affords me sincere pleasure to acknowledge that $\mathrm{I}$ have been aided very materially and most intelligently in making the following collection of mono. syllabic nouns by a member of my seminary for Greek grammar, Mr. Henry Clarke, A. M., formerly Fellow and now Fellow by Courtesy of the Johns Hopkins University.

${ }^{3} \mu$ \&í is wrongly perispomenon in Stob. Ecl. 1,27, p. 556 ; see Chandler $\S 566$. 
$\sigma \pi \lambda \eta_{\nu}$ 'spleen': Ved. plihhán-, Zd. spereza-, Lat. liēn, Old Bulg. slezena.

$\theta \dot{\eta} \rho$ ' wild beast,' Lakon. $\sigma \dot{\eta} \rho$, Aeol. $\phi \dot{\rho} \rho$ : Lat. ferus.

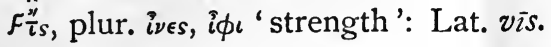

$\theta \dot{\omega} s, \theta \omega o ́ s$, stem $\theta \omega F_{-}$' jackal ' from root $\theta_{\epsilon} \mathcal{F}$, Sk. dhĩ v 'to run.'

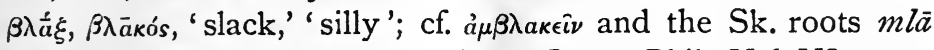
'to wither,' mlech ' to babble.' Cf. Am. Journ. Phil., Vol. VI, p. 48. $\phi \dot{\omega} \rho, \phi \omega \rho o ́ s, ~ ' t h i e f ': \phi \epsilon ́ \rho \omega ;$ cf. Lat. für, füris.

$\sigma \phi \dot{\eta}^{\prime} \xi, \sigma \phi \eta \kappa o ́ s$, Doric $\sigma \phi_{a}^{d} \xi$, $\sigma \phi \bar{a}$ кós: Lat. vespa, OHG. wefsa, Lith. vapsà (?).

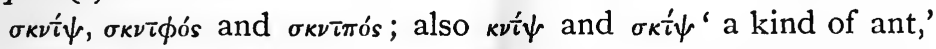
cf. Old Bulg. sknipa 'culex'; cf. Lob. Par. I I4, Cu. Etym. ${ }^{5} 694$. $\dot{\rho} \iota \dot{\iota} \psi, \grave{\rho} \iota \pi o_{s}$, ' mat': Lat. scirpus, OHG. sciluf; cf. Cu. ${ }^{5} 35^{2}$.

$\chi \epsilon i \rho$, Dor. $\chi \eta^{\prime} \rho$, ground form, in Timocreon fr. 9 B., $\chi^{\epsilon} \rho s$ ' hand': Sk. härämi.

$\lambda \lambda_{i}^{\prime}$ 'smooth' (cf. $\left.\lambda \bar{\imath} \tau o ́ s\right)$, stem $\gamma \lambda \bar{\imath} \tau$ : Lat. glittus, Lith. glitìs 'smooth'; see Cu. Etym. p. 367.

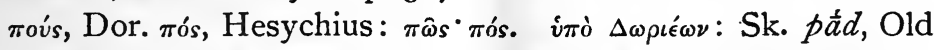
Norse föetr. The accent of noús is in no wise significant for the accentuation of long monosyllables in general, as this form of the nominative is certainly secondary; see $\mathrm{KZ}$. XXV i4. The writing; movेs occurs and is supported in some measure by the grammarians : see Lobeck Paralip. 93, Chandler 566 (p. 163 ). For Doric $\pi \hat{\omega} s$ see below, p. I5.

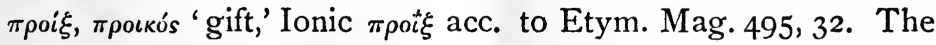
word is reported as perispomenon by Herodian, but apparently this is incorrect: see Göttling, p. 242, Chandler 566 (p. I63).

$\delta \rho \dot{\omega} \psi \cdot \stackrel{\iota}{\nu} \nu \rho \omega \pi o s$ (Hesychius). Probably a compound $=\nu(\delta) \rho-\dot{\omega} \psi$;

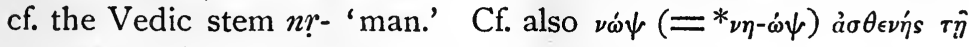
ठै $\psi \epsilon \iota$ (Hesych.); Lob. Par., p. I 18.

aik, ai yós 'goat.' There is some authority for the circumflex in Attic; see Lob. Par. 99; Chandler 566.

${ }^{\prime \prime} \lambda \xi=a \jmath \lambda \lambda \xi$ ' furrow.' $\widehat{\omega} \lambda \xi$ is reported in Orion and Arcadius ; see Lob. Par. I I I, Göttl. 242, Chandler 566 (p. I63).

$\pi \tau \dot{\omega} \xi$ 'crouching with fear'; cf. $\pi \tau \dot{\omega} \sigma \sigma \omega ; \pi \tau \hat{\omega} \xi$ is reported by a grammarian, Göttl. 243 .

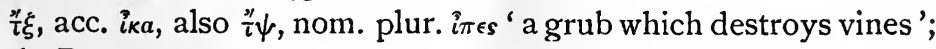
Lob. Par. pp. IO3. I04; Ior. I I5 ; Curtius Etym. ${ }^{5} 46$ I.

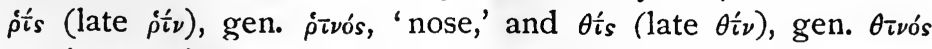
'heap,' are universally reported as oxytone, ${ }^{1}$ but there is good

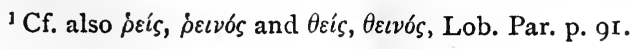


authority for both $\lambda \dot{t} s$ and $\lambda i$ ' 'lion' $\left(\mathrm{Cu}^{5}{ }^{5} 366\right)$, kís and kîs 'woodworm' (cf. Sk. kita?). The authorities are cited and discussed Göttl. 24I, Lob. Par. 92, Chandler 566 (p. 162), Misteli, Zur griechischen betonung, p. I 6 .

$\kappa \lambda \epsilon^{\prime}$ : Lat. clāvis, 'key.' Here also there is authority for the circumflex: Lob. Par. 92, Chandler 566 (p. 162). The Doric (Theocr. 15. 33) $\kappa \lambda \lambda_{a}^{\prime} \xi, k \lambda \bar{a} \kappa o ́ s$ no doubt belongs here, though the mode of its derivation from $k \lambda$ eis is obscure.

$\theta \epsilon \dot{s}$, Doric $=\theta \epsilon o ́ s$, acc. $\theta \epsilon \hat{v} \nu$. The circumflex is reported: Chandler ibid. Likewise Doric $\lambda$ eús $=\lambda a ̂ a s$.

Furthermore the following are unanimously reported as oxytone: $\beta \lambda \eta^{\prime}$ 'thrown': root-forms $\beta \epsilon \lambda \epsilon^{-}, \beta \lambda \eta-; \pi \lambda \dot{\omega} s$, 'swimmer': $\pi \lambda \lambda^{\prime} \omega, \pi \lambda \dot{\omega} \omega$;

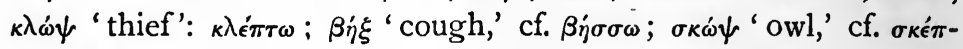

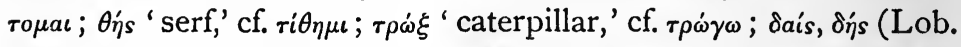

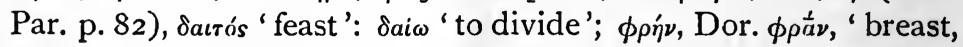
mind'; $\theta \epsilon i \rho$ 'louse'; $\rho \dot{\eta} \nu$ (late) 'lamb,' cf. Curtius, Etym. ${ }^{5}$ p. 345;

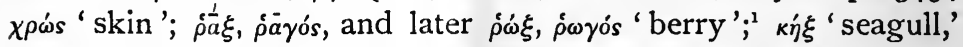

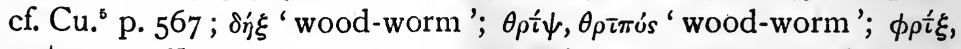

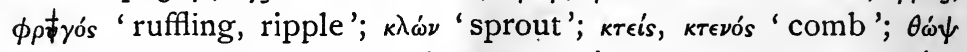

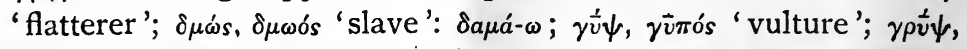

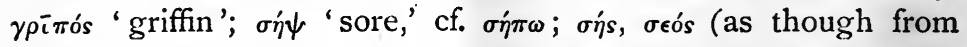

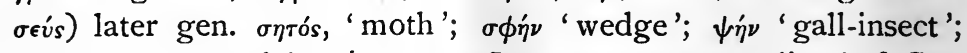

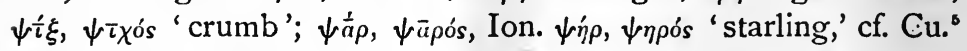
355 ; $\dot{\rho} \omega \dot{\psi} \psi$ 'brushwood '; $\pi \rho \dot{\omega} \xi$ 'dew-drop'; $\pi \dot{v} \xi$, $\pi \grave{v}$ yós, late form of $\pi v \gamma \eta$ ' buttocks'; $\gamma \lambda \lambda_{\eta} \nu$, late form for $\gamma \lambda \dot{\eta} \nu \eta$ 'púpil'; $\kappa \dot{\eta} \rho, \kappa \eta \rho o ́ s$,

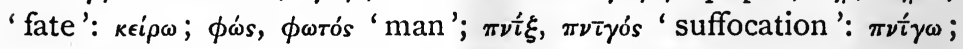

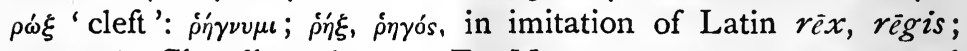
$\sigma \dot{\omega} \rho, \sigma \epsilon i \rho$, Chandler $56_{5}$; $\omega \varkappa$, Et. Mag. 344, 55, gen. $\dot{\omega} \pi o^{\prime}$ ' eye,'

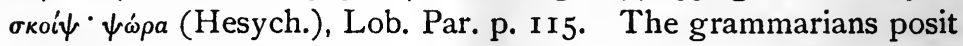

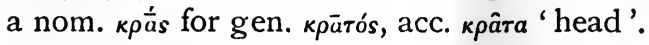

For $\delta o u ́ \xi$ and $\delta \rho \eta \dot{\xi}$ see Lob. Par. p. 102 ; $\delta \dot{\omega} s$ (Cu. ${ }^{\circ}$ p. 237 writes

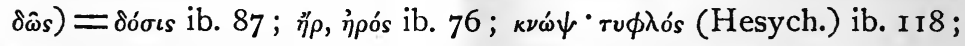

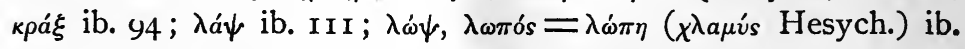

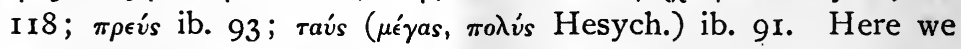
may mention $\chi \rho \eta$ (G. Meyer, ${ }^{2}$ p. 430) if the word is indeed of substantival origin.

The following proper names consisting of a long monosyllable are oxytone:

Zєís, Boeot. $\Delta \epsilon \dot{u}_{s} ; \mathrm{Z}_{\eta}^{\prime} s$ (owes its $\eta$ to the accus. $z_{\hat{\eta} \nu}$ : Herodian 2. 9II. 9, from Pherecydes), Dor. Zás (ibid.); $z_{\eta}^{\prime} \nu$, Dor. $z_{a}^{\perp} \nu$, Boeot. $\Delta \eta^{\prime} \nu$,

${ }^{1}$ Cf. also $\delta \rho \tilde{a} \xi$, Lob. Phryn. p. 76 ? 
hysterogenous nominatives abstracted from gen. Z $\eta \nu o ́ s, ~ Z \bar{u} \nu i$. All nominatives except Aeolic Z żv̂s agree in their oxytonēsis. Cf. G. Meyer, Gr. Gramm. ${ }^{2}$ 324. The following also are oxytone: 'P $\dot{\omega} \nu$,

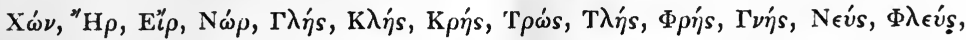

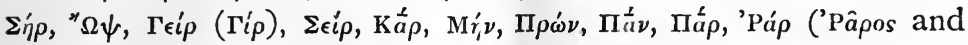

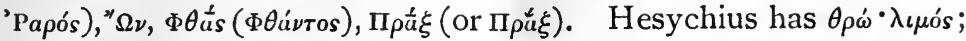
$\Sigma \kappa \omega \dot{~ \pi a \imath \delta i \sigma \kappa \eta ~(s e e ~ L o b . ~ P a r . ~ ' 120) . ~ F o r ~ " A \iota \rho ~ s e e ~ L o b e c k ~ P a r . ~ p . ~ 74 ; ~}$

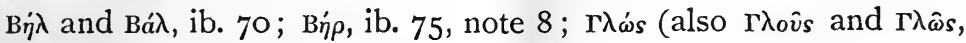

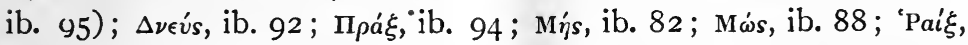

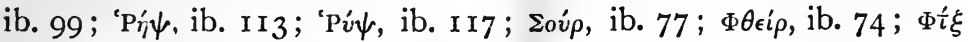
(Boeot. or Doric for $\Sigma \phi i \gamma \xi$ ), ib. Io4.

The following particles consisting of a long monosyllable are oxytone : $\mu \dot{\eta}$, Boeot. $\mu \epsilon^{\prime}$, Elian $\mu \bar{a},=$ Vedic $m \dot{a}, Z$ d. and Achem. $m \vec{a}=$

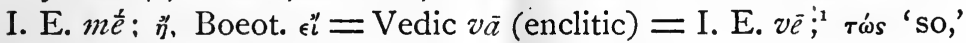
perhaps $=$ to an I. E. ablative tód plus a later $s$; “ss 'so,' a corresponding form of an I. E. stem ino- (also $\tilde{s}$; cf. Chandler, §934);

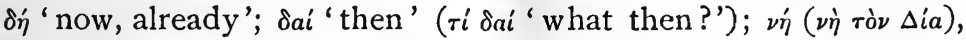

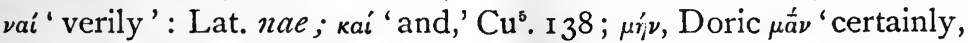
truly '; $\pi \lambda_{\eta \prime}^{\prime}$ (Doric $\pi \lambda \frac{\dot{a}}{a} \nu$ ), Cu. ${ }^{5} 28 \mathrm{I} ; \delta \eta^{\prime} \nu$, Hyper-Doric $\delta \dot{a}^{\prime} \nu$ 'long, for

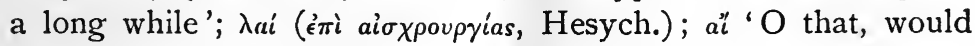
that'; ö, interjection of pain; $\ddot{\omega}$, interjection of pleasure and pain; Boeotian roúv, rov' 'thou,' are oxytone; roi is the Argive form for

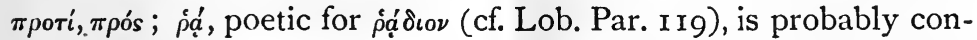
tracted from a dissyllabic form: see Osthoff, Perfect, p. 447 , note; for $\beta \rho a ́$ see ibid.; $\phi \eta$ 'as, like,' $\mathrm{Cu}^{5}$. 394, occurs both as $\phi \dot{\eta}$ and $\phi \hat{\eta}$. The scope of the circumflex in long monosyllabic nouns is as follows :

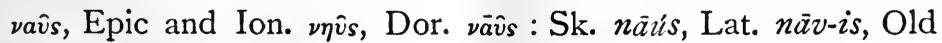
Pers. nävi, Old Irish nau.

$\beta_{o} \hat{s}$, Dor. $\beta \hat{\omega} s$, accusatives $\beta o \hat{\nu} \nu$ and $\beta \hat{\omega} \nu$ : Vedic gāús, acc. sg. gám, acc. plur. gáa, Zend gāo, OHG. chuo, Lettish gìwis, Old Bulg. govędo, (Lat. bōs).

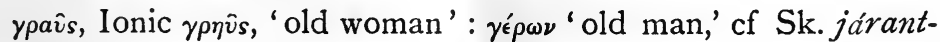
'old man.'

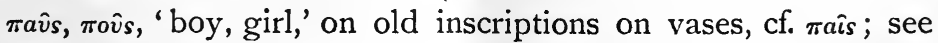
Benfey Wurzellexicon II 73, $\mathrm{Cu}^{5} .287$, Gust. Meyer Gr. Gramm. ${ }^{2}$ p. 3I2, note. The circumflex may be assumed upon the basis of

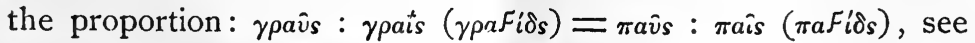
Meister, Zur Griechischen Dialektologie, p. 2.

${ }^{3}$ A very different view is advanced by Froehde in Bezz. Beitr. VII $327 \mathrm{fg}$. and supported by Osthoff, Zur Geschichte des Perfects, p. I28-9. 


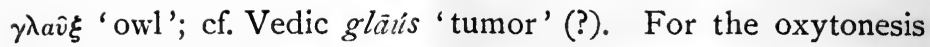
of the word in Doric see below. ${ }^{1}$

oủs, Cretan and Laconic aủs, Ionic sิs (inscription from Delos), Doric iss 'ear': Lat. aus-culto, aur-is, OHG. ōrā, Lith. aus-is, Old Bulg. uch-o (Gen. uš-es-e), Old Irish ó. The declension is heteroclitic: the stem of the oblique cases is ov $a-\tau=*_{o v \sigma-\nu \cdot \tau}=$ I. E. ous-n-, contained in Goth.stem ausin-, nom. auso, gen. ausins. See De Saussure, Mémoire, p. 224. ${ }^{2}$

$\mu \hat{v} s$, acc. $\mu \ddot{v} \nu$, 'mouse' : Sk. mìus, Lat. müs, OHG. müs, Old

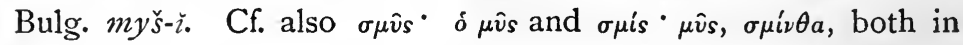
Hesychius.

$\sigma \hat{s} s$ and $\hat{v} s$ 'swine': Zend $h u$, Lat. sī-s, OHG. sü, NHG. sau; cf. also Sk. sü-karás, Old Bulg. sw-inija, Goth. sv-ein. Accusatives $\sigma \hat{v} \nu$ and $\hat{v} \nu$.

$\delta \rho \hat{v}$ ' tree, oak' : Sk. dru-s, Zd. dru, Goth. triu, AS. treozw, Engl. tree.

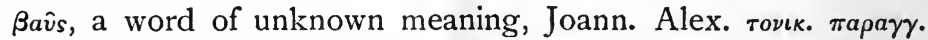
pp. 7, 35; see Lobeck Paralip. p. 91; Chandler 566 (p. 162). Cf. also $\beta a \hat{v} \cdot$ 'îंos ${ }^{\prime} \nu$ Oovs (Hesych.)

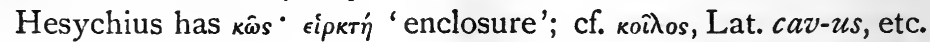
$\mathrm{Cu}^{5}$, p. ${ }^{\mathrm{I}} 57$.

$\gamma \hat{\eta}$ (Ionic-Attic) $\gamma \hat{a}$ (Doric), 'earth.' The contraction from Ionic $\gamma^{\prime} a$ or from $*_{\bar{a} a}\left({ }^{*} \gamma \eta o^{-}\right.$in Attic $\left.\gamma \epsilon \omega^{-}\right)$is unproved. The etymology seems unknown. See Cu. Etym. ${ }^{5}$, p. I77; G. Meyer ${ }^{2}$, p. 200 , note 2 .

$\beta \lambda \hat{\eta} \rho=\delta \delta^{\prime} \lambda \epsilon a \rho$ 'bait' is Aeolic ; the circumflex therefore proves

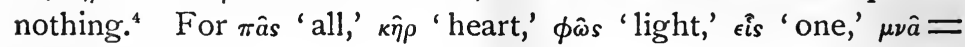
mina, see below.

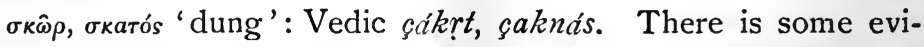
dence in favor of oxytonesis; see Lobeck Par. 77, Chandler 564; Liddell and Scott, sub voce. The Dorians are reported to have accented $\sigma \kappa \dot{\omega} \rho$; see below.

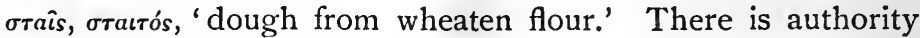
for $\sigma \tau a i s$ also: Lob. Par. 88. For $\kappa \rho a \hat{\jmath} \xi$ and $\kappa a \grave{\imath} \xi(?)$ see Lob. Par., p. IOO; $\pi \hat{a} s$ ibid. 78; $\sigma \tau$ ooùs (Hesych) ibid. 93. Hesychius has also $\sigma \chi \bar{v} \rho \cdot{ }^{\cdot} \chi^{i ̂} \nu o s$.

${ }^{1}$ For traces of oxytone $\gamma \lambda a v^{\prime} \xi$ outside of the Doric dialect see Lobeck Paralip. ro9; Chandler $\$ 566$; R. Meister, loc. cit., p. 3 ; Liddell and Scott, sub voce.

${ }^{2} \mathrm{G}$. Meyer's explanation of ov s as a contract form from *ovoos, *óvos, *ǒos does not seem to me a likely one, see Gramm. ${ }^{2}$, p. 326.

${ }^{3}$ For Doric $\delta a \tilde{a}$ see Ahrens, Dial. Dor. p. $80 ; \mathrm{Cu}^{5}$ p. 492 ; for Cypriote $\zeta \tilde{a}$ G. Meyer ${ }^{2}$, p. 200, note 2. $\quad{ }^{4}$ Etym. Mag. and Hesychius report $\beta \lambda \eta \dot{\eta} \rho$. 
Neuter nouns consisting of a long monosyllable are regularly

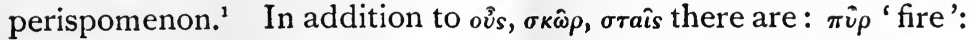
Umbr. pir, OHG. fuir, fur. Herodian 2, 919, cites a form nuï from Simonides of Amorgus, which leaves room for the suspicion that $\pi \hat{v} \rho$ is contracted. But the genitive $\pi v$ oós (with gradation of stem and shift of accent), as well as Umbrian pir (cf. sim and sif, probably equal to Gr. $i v$ and $i s$ ), points to the independent origin of $\hat{v}$ in the word; $\phi o \hat{v}$, probably the Pontic name of the plant valerian; $\dot{\rho} \hat{n}$, 'rha barbara'; $\delta \hat{\omega}$, Epic for $\delta \hat{\omega} \mu a$ ' house';

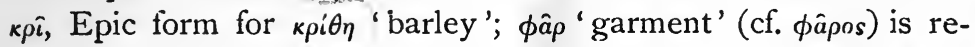
ported by Arcad. I 24 as perispomenon: Liddell and Scott write

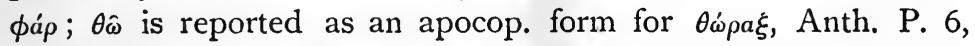

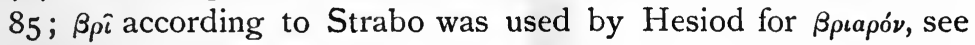
Liddell and Scott sub $\beta \rho \tau$ ii. For $\sigma a \hat{\nu}$ (and $\sigma a ́ \nu$ ) see Lob. Par. 77 ; for $\sigma \pi 0 v$ ibid. I20. The names of the letters are of neuter gender and perispomena : $\mu \hat{v}, \nu \hat{v}, \xi \hat{\xi}, \pi \in \hat{\imath}(\pi \hat{\imath}),{ }^{2} \rho \hat{\omega}, \tau a \hat{v}, \phi \in \hat{\imath}(\phi \hat{\imath}), \chi \epsilon \hat{\imath}(\chi \hat{\imath}), \psi \hat{i}, \hat{\omega}$.

Monosyllabic accusatives singular, long in quantity, are peri-

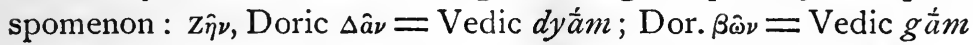

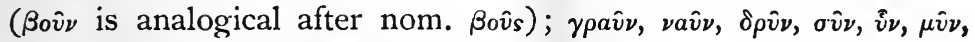

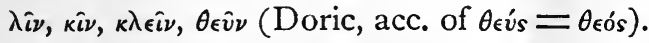

The corresponding plurals are also cirfumflected: Dor. $\beta \hat{\omega} s$ (Theocr. 8, 47) = Vedic $g^{\frac{1}{u}} s$, Zend $g \bar{a} o$. The primary character

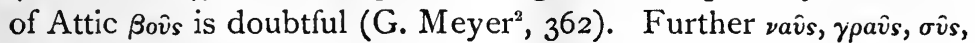
iss, $\delta \rho \hat{v} s, \mu \hat{v} s, k \lambda \in i$.

The following proper names are perispomenon: $\Theta \hat{\omega} \nu, T \rho \hat{\eta} s, \Sigma \hat{v} \rho$,

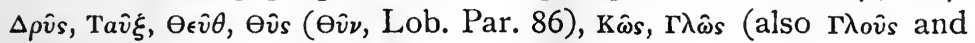
$\Gamma \lambda \hat{\omega} s), \mathrm{X} \hat{\omega} s, \mathrm{~T} \lambda \hat{\omega} s, \mathrm{~K} \rho \hat{\omega} s, \Lambda \hat{\omega} s, \Lambda \hat{a} s, \beta \nu \hat{\omega} \nu$ (? Chandler, p. I62, note I), $\Theta \rho \hat{a} \hat{\xi}$, Ionic $\Theta \rho \hat{\eta} \iota \dot{\xi}$, Homer and the tragedians $\Theta \rho \hat{\eta} \hat{\xi}$ (contracted?),

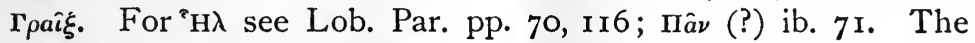
remaining ones are of the first declension: $\Gamma \rho \hat{a} s, \mathrm{Bâs}, \mathrm{X} \nu \hat{a} s, \Pi a \hat{s}, \theta \hat{a} s$, $\Delta \hat{a} s, \Delta p \hat{\eta} s ; \Phi \lambda \hat{a}$ (Herod. 4, I78: our editions read $\Phi \lambda \hat{a}$ ). For $\Pi \rho \hat{a} s$

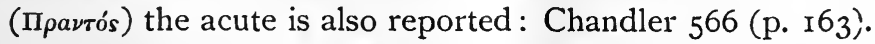

The following particles consisting of a long monosyllable are perispomena: $\nu \hat{v} \nu$ 'now': Sk. $n \bar{u}$ (and $n u$ ), Zend $n \bar{u}$, Old Bulg. nyně; Ionic, Aeolic, Boeotian and Doric ఏ̊v, Attic oủv 'then'; a 'again': Lat. aut, autem; $\hat{\eta}$ 'truly' (cf. $\eta^{\prime}$ above); $\hat{\omega}$, vocative

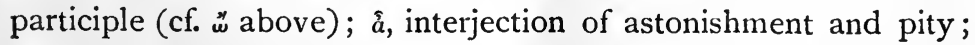
$a \imath$, interjection of wonder, blame, etc. : Lat. $a i$, a loan-word (cf. $a \imath$

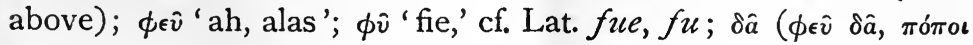

${ }^{1}$ Cf. Chandler, $\$ 563$; Phil. Anzeiger for I883, Vol. XIII, p. 580.

${ }^{2}$ Cf. Meisterhans, Grammatik der Attischen Inschriften, pp. I, 24. 


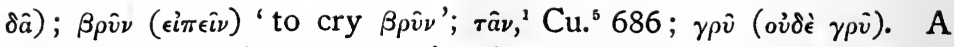
number of particles, representing frozen case-forms of pronominal stems, are perispomena: $\pi \hat{\eta}, \kappa \hat{\eta}, \pi \hat{a}$, but also $\pi \dot{\eta}, \kappa \dot{\eta}$ enclitics with supplementary accent ; $\tau \hat{\eta}$, $\hat{\eta}$, etc. (old instrumentals: G. Meyer ${ }^{2}$, p. 365 ); $\pi \circ \hat{\imath}$, oî (locatives); $\pi o \hat{v}$, ovं, genitives ; $\pi \hat{\omega} s,{ }^{2} \kappa \hat{\omega} s$, $\hat{\omega} s$ (also $\tilde{\omega} s$ : ablatives), etc. The circumflex of these particles is no doubt in many cases old, antedating the period of the recessive accent, as in $\pi 0 \hat{\text {, }}$ oi (cf. Hanssen in KZ. XXVII, p. 6I4), or a genuine rhetorical circumflex, as in interrogative particles and interjections. They are given here for the sake of completeness. Similarly $\pi \hat{a}$, $\beta \hat{a}, \mu \hat{a}$ are hypocoristic vocatives, and have vocative accent.

The report that the Aeolians circumflected every long monosyllable: $Z \epsilon \hat{v} s, \hat{\rho} \hat{\omega} \xi, \pi \tau \hat{\omega} \hat{\xi}, \delta \rho \hat{\omega} \psi, \chi \hat{\eta} \nu$, etc., is universally accepted, and accords with the remaining facts of the Aeolian system of accentuation; see Ahrens, Dial. Aeol., p. II ; Anton Führer, Ueber den lesbischen Dialekt,. p. viii. There is, however, a report of Choeroboscus, somewhat doubtful as to its meaning and scope, to the effect that the Aeolians treated monosyllables as oxytones, and there are also special reports to the effect that individual long monosyllables in Aeolic received the acute. Cf. above sub vocc. $\mu \eta^{\prime} \nu$ and $\beta \lambda \hat{\eta} \rho$, and Chandler $\$ 567$. I see no good reason to doubt the universally accepted perispasis of long monosyllables in this dialect.

The Dorians are reported to have accented $\gamma \lambda a v \dot{\xi} \xi$ and $\sigma \kappa \omega \dot{\rho}$ in distinction from Attic $\gamma \lambda a \hat{v} \xi$ and $\sigma \kappa \hat{\omega} \rho$; see Göttling, p. 243 ; A hrens, p. 27 ; Johannes Schmidt, KZ. XXV I4; R. Meister, Zur Griechischen Dialektologie, p. 3 ; Hanssen, Philologischer Anzeiger, XIII, p. 580. The temptation to see in this an instance of vacillation between etymological and recessive accentuation must be resisted. R. Meister (ibid.) believes that Doric $\gamma \lambda a v \dot{\xi}$ and $\sigma \kappa \dot{\omega} \rho$ have 'den alterthümlichen accent (i. e. no doubt what we here call etymological accent) gegenüber der im aeolischen dialekt regelmässig, im ionisch-attischen hier und da eingetretenen perispomenierung bewahrt.'

We must consider, however, that the Doric dialect exhibits many cases of suspended perispasis, as in $\pi \tau \dot{\omega} \kappa \epsilon s, \pi \tau \dot{\omega} \kappa u s, \pi a i \delta \epsilon s$,

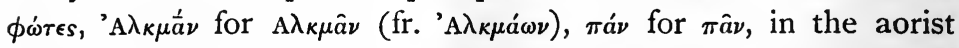
infinitives $\sigma \tau \dot{a} \sigma a l, \lambda \dot{v} \sigma a t, \delta \epsilon i p a$ and $a \mu \dot{v} \nu a l$, and that in general there is to be observed something like a 'processive' reaction against the 'recessive' tendency, the latter being probably Pan-Hellenic,

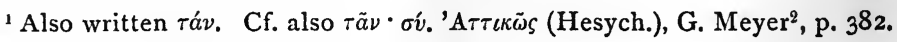

${ }^{2}$ Cf. $\pi \tilde{\omega} \cdot \pi o \tilde{v} . \tilde{\theta} \theta \varepsilon v . \pi \delta \dot{\theta} \theta \varepsilon v, \Delta \omega \rho \varepsilon \varepsilon i \zeta$, Hesych. 
but certainly Attic-Ionic and especially Aeolic. This is exhibited

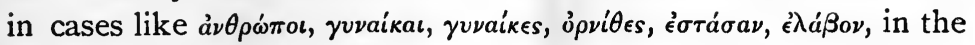
accentuation of $\pi a \nu \tau \hat{\omega} \nu$ (Göttl. 246), and $\phi \rho \vec{u} \tau \eta \dot{\rho}$ for Attic $\phi \rho \hat{a} \tau \eta \rho$, etc. These are certainly secondary whether they mark a secondary phonetic change or analogical transformation ( $\dot{a} \nu \theta \rho \dot{\omega} \pi \pi_{0}$ after $\dot{a} \nu \theta \rho \dot{\omega}-$

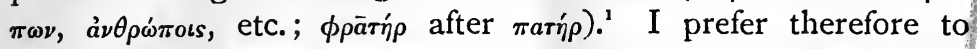
regard $\gamma \lambda a \hat{v} \xi$ and $\sigma \kappa \hat{\omega} p$ as the oldest forms on Greek ground, and to consider the coincidence of the Doric accentuation $\gamma \lambda a \dot{v} \xi, \sigma \kappa \dot{\omega} \rho$ with the etymological accent as accidental.

Hence I cannot subscribe to Wheeler's first comparison in support of his thesis that monosyllabic words have retained their etymological accent unchanged. He writes Doric $\pi \dot{\omega} s(!)^{2}=\mathrm{Sk}$. $p a \hat{a} d=\mathrm{I}$. E. póts. As far as I know the only source upon which

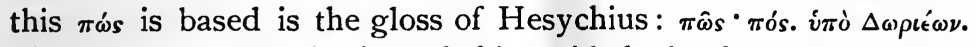
In writing $\pi \dot{\omega} s$ Wheeler is probably guided-he does not say soby the consideration advanced by Joh. Schmidt in KZ. XXV I4. The latter judges from the reported oxytonesis in Doric of $\gamma \lambda a v$ and $\sigma \kappa \dot{\omega} \rho$ that Hesychius has misreported this accent, as he frequently does. Whether this be so or not, even the hypothetical Doric $*_{\pi \dot{s}}$ is not to be compared directly (as Schmidt and Wheeler do)

${ }^{1} \mathrm{R}$. Meister in his very thoughtful tract, Zur Griechischen Dialektologie (I. Bemerkungen zur dorischen Accentuation) endeavors everywhere to explain these cases of 'procession' as due to one of two causes : either some analogy within the paradigm of the word in question, or to a suspension of the $\pi \varepsilon \rho i \sigma \pi a \sigma \iota s$ $\kappa a \tau \eta v a \gamma \kappa a \sigma \mu \varepsilon ́ v \eta$ of the other dialects. I do not believe that he is on the right track, as he does not point out any reason why the manifold special phenomena of accent in Doric agree in promoting the accent towards the end of the word. If looked at in detail, special causes may be found readily enough for every instance of Doric procession : $\dot{a} \nu \theta \rho \dot{\omega} \pi \omega \iota$ might well be accented after $\dot{a} \nu \theta \rho \omega \tilde{\omega} \omega \nu$;

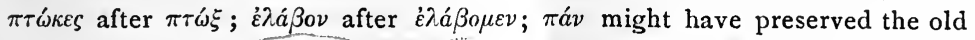

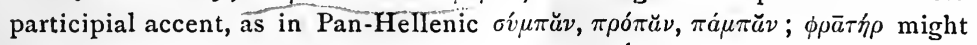

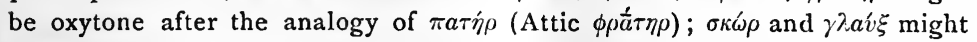
represent instances of preserved I. E. oxytonesis in Doric, etc., etc. Yet each one of these explanations-quite reasonable when considered singly-is rendered improbable because they all operate in the same direction. Why do not some of these Doric accentual modifications operate in the other direction, i. e. 'recessively,' if they are merely the results of individual effects? Unless we wish to burden the Dorians with an apparently teleological choice of such analogies as tend to 'procession,' we must assume that the reported Doric instances of 'processive' accent-they are not actually quotable in the language-are due to some single fact in accentual phonetics whose scope and cause we are unable to determine owing to the deficiency of the tradition. We will encounter later on the same difficulty in Wheeler's (and Prellwitz's) attempts to explain the phenomena of Aeolic accentuation.

${ }^{2}$ See p. 13, as also Prellwitz, loc. cit. p. 764 . 
with Sk. pád, I. E. póts, but may be as well regarded as a secondary Doric product out of Pan-Hellenic * $\pi \hat{\omega} s$, as long as an AtticIonic $\pi \dot{\omega} s$ is not discovered. ${ }^{1}$

$\pi \hat{a}$ s and neuter $\pi \hat{a} \nu$ are of especial interest, as illustrating the existence of recessive accentuation in monosyllabic nominal stems. They represent an I. E. non-thematic participle $=$ Sk. * çánt-, I. E. kuñt-. This conclusion may be derived from Benfey's old discovery that Sk. çáç̧ant-, for *sá-çvant, is Greek $\ddot{a}$-ravt-; see Wurzellexicon II I67; Orient und Occident I 573 ; "Das indogermanische Thema des Zahlworts 'zwei' ist DU," Abhandlungen der Gesellschaft der Wissenschaften zu Göttingen, XXI 7. The word $* \pi \frac{1}{a}$ s lost its connection with any finite verbal system very early: hence the recessive accentuation, avoided by other participles, lodged within a finite system, forms like $\phi^{\frac{1}{a}} s, \beta_{a}^{\prime} s, \tau \lambda \hat{a}^{\prime} s$, etc.; see above. On the other hand the Attic genitive plur. $\pi a$ r $\tau \omega \nu$, dative plur. $\pi \hat{a} \sigma \iota$ are still participial like $\beta a ́ v \tau \omega \nu, \sigma \tau a ́ v \tau \omega \nu$, etc. The

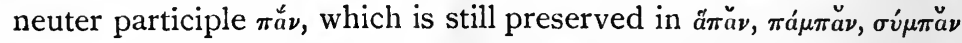
and $\pi \rho o ́ \pi \check{\nu} \nu$, in changing to $\pi \hat{a} \nu$, adopted both the quantity and accentuation of $\pi \hat{a} ._{.}{ }^{2}$

I have left out of question the perispasis of the vocatives of long monosyllabic nouns. At first sight this is one of the strongest proofs of the recessive character of the circumflex in cases like vav̀s, etc. The classical example $Z \epsilon \hat{v}$, circumflexed vocative: Zeús, oxytone nominative, is reflected in Vedic djyas, vocative with independent svarita: dyāııs, nominative with udātta. Each pair goes back to I. E. couplet $d \widehat{i \bar{c} u}(s)$, vocative with I. E. independent svarita: deterus, nominative with acute accent. But the very antiquity of the recessive accent in the vocative makes it chronologically unfit as an argument for the recessive character of the type

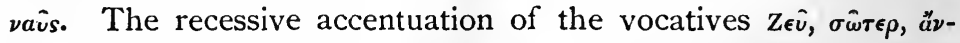
$\theta \rho \omega \pi \epsilon$, etc., is proethnic; that of vaìs at best Pan-Hellenic. That does not exclude the fact that both processes, the old recession of the tone in the vocatives to the first mora $(Z \in \hat{v})$, and the substitute for enclisis which is contained in the last resort in vaîs, have finally worked to the same end, but the recessive accent in $z \in \hat{v}$ does not directly prove that the circumflex in vaîs is also recessive. Cf. also the note on $\mathrm{p}$. I7.

${ }^{1}$ Of course the oxytonesis of $\pi$ ov's proves nothing for $\pi \omega s$, as the entire, ending (-ov́s) is secondary; cf. above s. v. $\pi$ ov́s, and G. Meyer, ${ }^{2} \$ 77,313$. The latter also writes $\pi \omega s$ in both places.

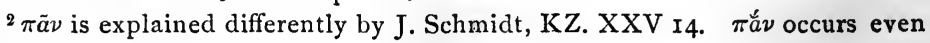
outside of composition proper, e. g. Pind. Ol. 2. 93. 
A theory which ignores in its consideration of long monosyllables so important and far-reaching a difference as that exhibited in the collection above is not calculated to inspire confidence. Wheeler does not anywhere allude to it; much less does he make an effort to explain it away. Though such an attempt seems in any case an after-thought, I have nevertheless surveyed the ground as carefully as possible for some expedient by which the circumflex accent of the type $\nu$ ais and Aeolic $Z \epsilon \dot{\nu} s, \pi \tau \hat{\omega} \xi$, etc., might be explained without the assumption of recessive accent. But I cannot say that I have succeeded in finding one. Hanssen in KZ. XXVII 6I 2 f., by employing successfully Leskien's important little article 'Die Quantitätsverschiedenheiten im Auslaut des Litauischen,' Archiv für slavische Philologie, I88I, Vol. V, p. I 88 fg., has proved that a kind of circumflex accent ${ }^{1}$ existed quite extensively on final syllables of words in I. E. times, but his proof does not include a single case of a monosyllabic noun-stem, nor indeed a single monosyllable. I hold myself ready to accept the original character of the circumflex wherever there is good ground to accept it. Hanssen may perhaps not have gone far enough in his assumption, or at least in the express statement of such accentuation, inasmuch as he gives only examples in which at least two of the languages compared (Greek, Lithuanian, and Gothic) testify directly to the exist-

1 At least it appears as the ordinary circumflex in Greek. It is in reality that accentuation of a long syllable in which the summit-tone either permeates the two moras of which the syllable consists, or in which there is double summit accentuation (Sievers' Phonetik ${ }^{3}, 203$; Bloomfield, Historical and Critical Remarks, 27-8). In Lithuanian grammar this mode of accentuation is called ' geschliffener ton,' after Kurschat's precedent. 'Geschliffener ton' is a misnomer for 'geschleifter tơn' (Leskien orally: Brugmann, Grundriss, I, p. 562, suggests 'schleifende' sc. betonung). We may designate in English this mode of accentuation by the term 'drawled tone,' or 'slurring tone' (in the acceptation of the word in music). This I. E. drawled tone probably has a very definite scope (see Hanssen above), and we must for the present keep it differentiated from the genuine I. E. circumflex (svarita) of $\mathrm{Z} \varepsilon \bar{v}=$ Vedic $d \bar{y} \bar{a} u s$ which is the result of the fusion of an acute plus a grave $\left(^{\wedge}\right)$. In the ordinary

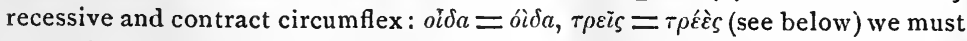
recognize a third type of circumflex, phonetically very similar to the second, but chronologically very different, inasmuch as the earliest date which we can assign to it is the Pan-Hellenic period. Even that is probably too early for the contract circumflex; see G. Meyer, ${ }^{2}$ p. I40. Heterogeneous accentual materials of the Greek have become fused by one mode of designation. In Sanskrit the first two kinds are designated respectively by the genuine svarita and the udatta; the enclitic svarita (Whitney, $\$ 85 \mathrm{fg}$., Historical and Critical Remarks, p. 45) generally takes the sign of the genuine svarita. 
ence of the circumflex. For $\pi \circ \delta \hat{\omega} \nu=\mathrm{Sk}$. padấm we may suppose an I. E. pedom with 'drawled' or 'slurring' tone (see the footnote

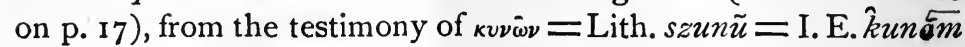
(despite çinām, Atharva-Veda III 9, 4). Accordingly it seems to me not unlikely that the perispasis of long monosyllabic accusatives sg. and pl. may be founded upon this I. E. 'drawled' ('slurring') tone, although the nature of the case is such that we may perhaps never be in the position to prove it. If we survey the list given above: sg. $Z_{\hat{\eta}} \nu$, Dóric $\Delta \hat{a} \nu$; Doric $\beta \hat{\omega} \nu$, Attic $\beta o \hat{\nu} \nu, \gamma \rho a \hat{\nu} \nu, \nu a \hat{\nu} \nu, \delta \rho \bar{\nu} \nu$,

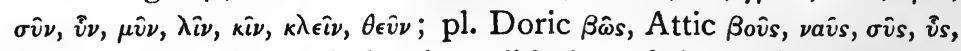
$\delta \rho \hat{v} s, \mu \hat{v} s$, we are struck by the solidarity of the perispasis. Yet much of it is palpably secondary: Doric $\Delta \hat{a} \nu$ has a Hyper-Doric $\hat{a}$,

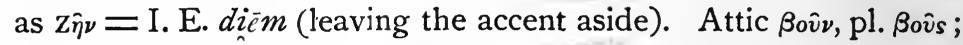

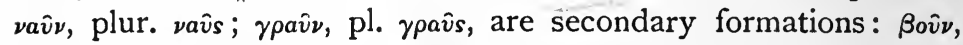
$\nu a \hat{v} \nu$ and $\gamma \rho a \hat{v} \nu$ after the pattern of the nominatives sg. $\beta o \hat{v} s, \nu a \hat{v} s$, and

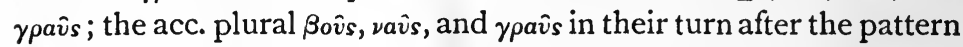
of the acc. sg. $\beta o \hat{v} \nu, \nu a \hat{v} \nu$, and $\gamma$ paiv. The accusatives $\mu \bar{\nu} \nu$ Sg., $\mu \hat{v}$ s pl. are also secondary issue of the nom. $\mu \hat{v}$, inasmuch as the stem is $\mu \bar{\nu} s=$ I. E. muis-; the proper accusatives are ${ }^{*}{ }_{\mu \nu} \dot{v}$ for ${ }^{*}{ }_{\mu \bar{v} \sigma a}$ and $\mu \bar{v} a s$ for ${ }^{*} \mu \hat{v} \sigma a s$ (cf. G. Meyer ${ }^{2}$, pp. 32I, 346). $\quad \kappa \lambda \epsilon \hat{i \nu}$ and $\kappa \lambda \epsilon i$ s are pretty certainly secondary to $\kappa \lambda \epsilon \hat{i} \delta a$, Hom. $\kappa \lambda \eta \hat{i} \delta a$, pl. $\kappa \lambda \epsilon i \delta a s$. Doric $\theta \epsilon \hat{\nu} \nu$ acc. to $\theta$ cís $=\theta$ cós can only be the product of a later propagation of the type, as the word is certainly originally a dissyllable. I do not venture to decide the question of the originality of the accusatives $\sigma \hat{v} \nu, \delta \hat{\nu} \nu, \delta \rho \hat{v} \nu,{ }^{1} \lambda \hat{\imath} \nu, \kappa \hat{\imath} \nu ;$ pl. $\sigma \hat{\imath} s$, ìs, $\delta \rho \hat{v} s . \quad$ G. Meyer ${ }^{2}, \S 33$ I says:

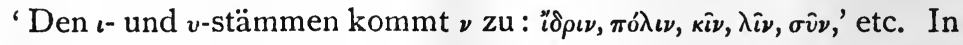

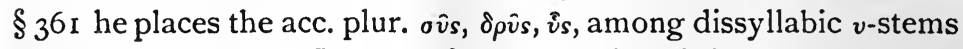
like $\gamma^{\prime} \nu_{\bar{v} s}, \nu^{\prime} \epsilon \bar{v} s$, etc. It seems from one point of view that we ought to expect for long monosyllabic stems accusatives of the type sg. óp$v^{\prime} a^{2}=$ Sk. bhrivam, Çatapathabrāhmaṇa III 2. 1. 29, and Homeric oppúas $=$ Sk. bhrivas. Cf. also Lat. suem. On the other hand Umbrian sim and sif point to $i v$ and $i s$. Be this as it may there remain in any case the accusatives $Z \hat{\eta} \nu, \beta \hat{\omega} \nu, \beta \hat{\omega} s$, where I believe that both form and accent are original. I venture the following reconstruction: $\mathrm{z}_{\hat{\eta} \nu}=$ Vedic $d y^{\dot{a}} m=\mathrm{I}$. E. $d \dot{i} \overline{\bar{e}} \overline{(\underline{u})} m ; \beta \hat{\omega} \nu=$ Vedic $g^{\frac{1}{a}} m=$ I. E. $3 \overline{o(u)} m ; \beta \hat{\omega} s=$ Vedic $g \bar{a} s=I$. E. $3 \bar{o} \overline{(\underline{u})} s ;$ i. e. I suppose that a slurring or drawled mode of summit accentuation accompanied the utterance of these monosyllables. Direct unequivocal proof of this

1 There is in the Rig-Veda no single case of an acc. sg. in -um.

2 The form occurs late, Oppian. Kyn. 4. 405, but can certainly make no claim towards direct identification with Sk. bhrivam despite the formal equality. 
assumption is impossible, as 'drawled' tone and udātta have the same designation in the Veda (see the footnote on p. r7), but the morphology of the forms renders it likely enough. This is the only instance in which the circumflex may be even approximately proved original in the case of long monosyllables, and even if we consider it not impossible that it may yet be proved proethnic in other monosyllabic words, ${ }^{1}$ it is nevertheless quite incredible that types in every other respect so perfectly parallel to $z \epsilon \dot{s} s=d y a \bar{u} i s$

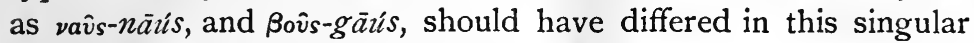
manner in their original accentuation.

I have thought of the analogy of contract forms. So $\eta_{\rho}$ (gen. $\hat{\eta}$ pos) is the lyric form for "ैap (Alcman 24); Attic ois = ois for ${ }^{\prime \prime} F_{\text {is }}$

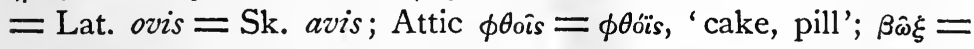

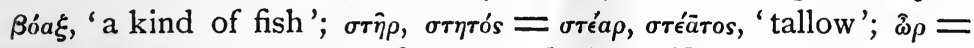

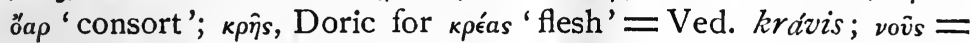

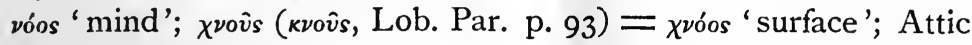
$\theta$ pov̂s $=\theta$ óos 'noise.' Attic $\chi \chi^{\circ} \hat{s}$ is declined as though it were

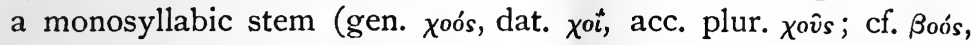

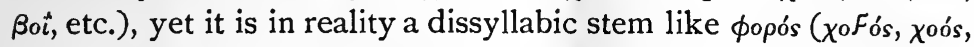

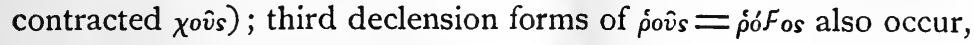
e. g. genitive óós like zoós; see Lob. Phryn. 454.

The epic word $\kappa \hat{\eta} \rho$, $к \hat{\eta} \rho \circ$ ' 'heart' is explained by Göttling, p. 425, Leo. Meyer KZ. V 69; Misteli, Über griechische Betonung, p. I I 8, as contracted from the later ḱa (tragic, lyric), in the same way as $\eta \hat{\rho} \rho$, $\eta_{\rho} \rho s_{\text {from }} \ddot{\epsilon} \alpha \rho$. Curtius, Etymologie ${ }^{6}$, p. I43, points out the independent character of the stem ( ${ }^{*} \kappa \hat{\eta} \rho \delta$ ?), and Brugmann, in Curtius's Studien IX 296, note, explains the accent as an imitation of the contract accent of $\eta \rho, \hat{\eta} \rho o s$. The persistence of the circumflex in the declension of the word renders this explanation

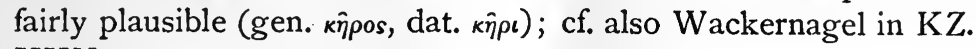
XXV 280.

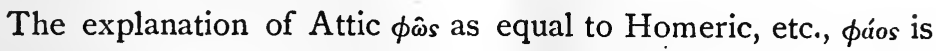
the current one; see e. g. Brugmann in Curtius' Stud. IV I73; G. Meyer', p. 326. No one as far as I know has, however, offered any explanation which bridges over the difference in the stems of the two words: $\phi \bar{a} \mathcal{F}_{\epsilon \sigma-}$ but $\phi \omega \tau-$. The stem $\phi \omega \tau-$ seems to me better comparable with Vedic bhäs, neuter in the oldest language, the $\tau$ being 'adscititious' (Brugmann, ibid.); cf. $\phi \omega \sigma-\phi o ́ p o s$ and bhäs-kara 'shining.' But the circumflex may be due to the fact

${ }^{1}$ The regularity with which long monosyllabic neuters are circumflected is worthy of attention; Chandler $\$ 563$ and above. 
that the form was felt to be associated with qúos as its contract form.

The difference between $\epsilon$ is (Doric ijs: Heraclean tablets I, I36) and oủotis, $\mu \eta \delta \epsilon i s$ (lacon. oủois IA. 79, 4) is as yet unexplained; cf. Göttling, 246; Misteli II8; Hanssen, Philologischer Anzeiger XIII, p. 580. The evidence of Attic roús = Kretic róvs, etc., points to the fact that the oxytone accent is the fundamental one, and that the perispasis of $\epsilon i s$ is secondary. I venture to propose the analogy of the contract circumflex of $\tau \rho \epsilon i s$ (Homeric and Attic) $=\tau \rho^{\prime} \epsilon s$ (Inscr. of Gortyna, 9, 48) $=$ Sk. tráyas $=\mathrm{I}$. E. tréies. The vigorous analogical influence of numerals upon one another has long been noticed; see Osthoff, Morphologische Untersuchungen I 92 fg. ; Baunack, KZ. XXV 225 fg. One can understand easily how

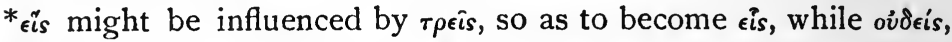
$\mu \eta \delta \in i$ 's would be preserved from this contamination by being 'out of the count,' and possibly by the blurred consciousness of the origin of the words.

The circumflex of $\mu \nu a ̂$ may possibly be due to its assumed derivation as a contract form from Ionic $\mu \nu \dot{y}^{\prime} a$ (Hdt. 2, I80); $\mu \nu \hat{a}$ is probably more original than $\mu \nu \boldsymbol{y}^{\prime} a$. It is Hebrew-Phoenician cf. Lat. minna, Sk. manà (also a loan-word); cf. Zimmer, Altindisches Leben, p. 50 .

The circumflexed form $\epsilon i$ ' thou art' I have explained previously in a totally different connection and from a different point of view, as owing its orthotonesis-in distinction from the enclisis of $\epsilon^{i \mu}$, isrı, etc. - to the analogy of verbal forms with the circumflex due to contraction: see Historical and Critical Remarks, p. 59 (39). I see no reason for retracting this view, and I am not aware that any authority has objected to it, or that a more plausible one has been advanced hitherto. ${ }^{1}$

Much of the perispasis of long monosyllables in Attic-Ionic may be in this way ultimately exhibited as secondary. The small investigation given above may serve rather as a guide in the matter, than lay claim to an exhaustive examination of the possibilities in that direction. Yet it seems to me that no one will be found willing to undertake the thankless task of explaining away all the instances of the circumflex on long monosyllables recounted above, without calling in the aid of that retraction of the accent which is an infallible law in the monosyllabic forms of the finite verb.

1 Osthoff's explanation of $\varepsilon \dot{\varepsilon}$, as equal to $\ddot{\varepsilon} \ddot{\imath}$ for I. E. ési, with 'nebentonigtieftonigem vocalismus des personal-suffixes' rests upon too slender a basis of fact to inspire confidence. See $Z$ ur Geschichte des Perfects, p. I8, note. 
And even the sturdiest determination in that direction would be of no avail on account of the Aeolic dialect. Wheeler has taken no account of the constant perispasis of long monosyllables in Aeolic, $Z \epsilon \hat{v} s, \pi \tau \hat{\omega} \xi, \chi \hat{\eta} \nu, \delta \rho \hat{\omega} \psi$, etc., etc. : we may assume that he has consistently placed circumflex and acute upon the same level here as throughout his work. Prellwitz, in his review, loc. cit. p. 757, recognizes this deficiency and proceeds to remedy it. But his processes do not in my opinion redound to the advantage of the cause. Prellwitz would explain the perispasis of $z \in \hat{v} s$ and $\pi \tau \hat{\omega} \xi$ as due to the analogy of $Z \hat{\eta} \nu, Z \epsilon \hat{v}, \pi \tau \hat{\omega} \kappa a$. This is well possible when taken by itself: it would be simple paradigmatic analogy. If we

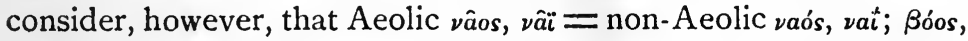
кúvos $=$ non-Aeol. Boós, kvvós, furthermore if we consider Aeolic

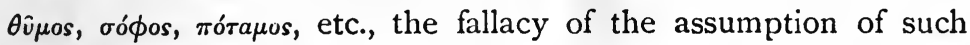
analogy becomes apparent. It is of the same sort as that criticized above in R. Meister's explanation of suspended perispasis in Doric: there is no reason provided for the infallible motion of these supposed analogies in one direction. I shall return to this point more fully later on in connection with Wheeler's explanation of the accent of Aeolic $\theta \hat{v} \mu o s$ and oópos. I fail to see how the assumption can be avoided, that certain accentual types, namely the 'recessive' ones, have propagated themselves in Aeolic without reference to the function of the forms involved.

Nor will it do to assume that the difference between acute and circumflex became indistinguishable at a period so early that the Homeric difference between $Z$ evis and vavis may be accounted as nonsignificant. Deutschmann, in his treatise De poësis Graecorum rhythmicae primordiis, Malmedy, 1883, p. 3, assumes this state of things for the first century A. D., but his assumption is fitly refuted by Hanssen in the Phil. Anz. XIII, p. 422. As late as Babrius the difference between acute and circumflex must have existed, for he categorizes words like kím $\mu \omega$ and roviro together, and differentiates $\kappa a ́ \mu \nu \omega$ and $\mu \eta^{\prime} \tau \rho$; cf. Hanssen, Rheinisches Museum XXXVIII, p. $239 \mathrm{fg}$. He could not have put the accentuation of $\kappa \dot{\mu} \mu \nu \omega$ and rov̀ro upon the same level without recognizing that the fundamental difference between acute and circumflex is rather a topical than a qualitative one. The acute accent on a long syllable means in reality that the second mora has the acute, the first one being grave; $\mu \eta^{\prime} \tau \rho=\mu \grave{\epsilon} \epsilon \eta \rho$; the circumflex on a long syllable means the accentuation of the first mora; roüro $=$ róviro. Hanssen, Phil. Anz. XIII, p. 422, without offering anything new, well describes 
the ordinary (not 'drawled') circumflex as follows: 'There is in fact in Greek but one (grammatical) accent, the acute; but this can fill but one mora. Short syllables therefore admit of but one kind of accentuation: their vowel carries the acute; syllables with a short vowel, long by position, also admit of only one kind of accentuation: their vowel bears the acute, they also have the tone on the first mora; syllables containing a long vowel (or a diphthong) admit of a twofold method of accentuation; the acute may stand on the first mora of the vowel (circumflex), or the acute may stand on the second mora of the vowel (acute on a long syllable). The designation of accent is deficient in marking an acute upon a short vowel and an acute upon the second mora of a long vowel by the same sign, and it is an unlucky circumstance that a special name and a special mark was not constructed for the acute on a long syllable, but for the circumflex. In reality the words a $\lambda^{\prime} s$ and $\pi$ oús, which carry the same accent-mark, are not accented alike, and they are not both accented differently from oủs, but ä $\lambda_{s}$ and oủs are accented alike on the first mora, while noús is accented on the second mora. The difference between acute and circumflex in all probability was given up along with the differentiation of short and long vowels, at a time when the difference in the pronunciation of $o$ and $\omega$ was given up; at that time the difference in the accentuation of $\tau \dot{\sigma}, \tau \hat{\varphi}$, and $\tau \dot{\omega}$ was no longer felt.'

This applied to vaùs and Zeús means that the accent of vaîs is vávis, that of Zeús is zèus.

The difference is a topical one, not one of quality only, and our previous considerations have made it probable that no other source than the recessive accent of the formally corresponding verbal forms will be found for accent of vavs, which deviates from the I. E. naius. The sporadic or unsettled character of the recession in the noun-types (vaîs, $\beta$ oùs but Zeús, $\beta$ áas) is, as far as I can see, well explained by the statements on pages $30,50,57$ and 62 of my treatise, quoted at the beginning of this paper. The recessive accent in the verbal forms is enclisis, or rather a substitute for it, therefore a grammatical quality, which covers the entire ground; in the noun it is secondary, no doubt analogical, apparently on the way towards absorbing it. This process of absorption is complete in the Aeolic dialect. The manner in which this analogy has operated I shall endeavor to delineate below.

The considerations given thus far are in themselves quite sufficient to unsettle one's belief in Wheeler's hypothesis, with its 
fundamental idea of a subsidiary tone. In his assumption of a subsidiary tone on the third or fourth mora from the end, there is

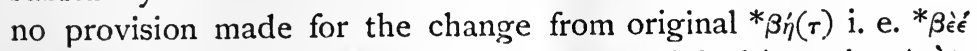

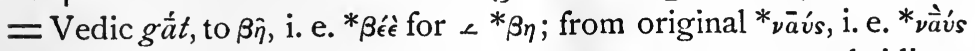
to vaìs, i. e. vávis. Here it would be necessary to assume a subsidiary tone on the second mora from the end. Will any one be found willing to believe that a single long syllable was burdened with a summit tone and a subsidiary tone, and that at a certain time, to use Wheeler's own terminology, 'trat ein Schwanken ein, das Später zu gunsten einer der beiden Accentuation ausfällt'?

I believe that enough has been said to show that that part of Wheeler's first thesis which refers to monosyllables is not tenable. Still less do I find myself in the position to adhere to the second part of it. The claim that dissyllabic forms with short final syllable retain the inherited (I. E.) accent seems to me quite groundless.

At all times comparisons like the following have been considered legitimate: oỉoa, oî $\theta a$, oî̉ $\epsilon=\mathrm{Ved}$. véda, vetth

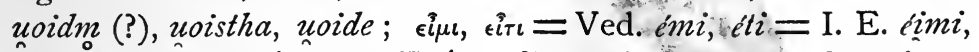
$\hat{e} i t i ; ; \hat{\eta} a=\hat{V}$ edic $\hat{a} s \hat{a}=\mathrm{I}$. E. ésmo (?), perfect ind. act. first sing.; $\hat{\eta} \in(\nu)=$ Vedic $\stackrel{b}{a} s a$, I. E. $\stackrel{e}{s} s$, perfect third sing.; dual and plural forms of the imperfect of the copula: $\hat{\eta} \sigma \tau o \nu, \hat{\eta} \mu \epsilon \nu, \hat{\eta} \sigma \tau \epsilon=$ Vedic

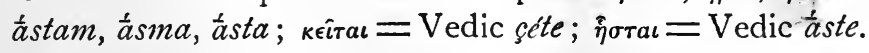

Comparative grammarians are usually pleased to speak of such cases as being equal sound for sound. But is it true that any respectable authority has ever ignored the thoroughgoing difference in the accent? There is absolutely no reason for doubting that the Vedic udātta of véda, émi, etc., represents the I. E. acute or 'cut' ('gestossen') tone on the second mora of the first syllable. To my knowledge no one has ever hinted at a similar accentual condition in the cases above ( $F_{0 i} \hat{\delta} \epsilon, \epsilon i \mu l$, etc.). The circumflex on verbal forms of this type: $\simeq \cup$, i. e. dissyllabic trochaic forms, has always been understood to be 'recessive,' utterly independent of any accentuation prior to Greek period. oi $\delta a=$ Vedic véda is 'recessive' precisely in the same sense as $\beta \hat{\eta}=$ Vedic $g^{\prime} a t$. No one will be found so bold as to assume a proethnic 'slurring' tone or a proethnic svarita (cf. p. I7, note) for all dissyllabic trochaic verbal forms, whatever their connection. The very fact that the

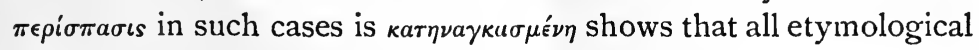
accentuation is superseded by the 'recessive' law.

In the case of long monosyllables, the verb is recessive, without exception: the noun, according to our discussion above, has 
followed the verb only to a certain extent. On the other hand the entire body of trochaic dissyllables: verbs, nouns, pronouns and other parts of speech are properispomena, ' aside from the Doric instances like $\pi \tau \dot{\omega} \kappa \epsilon s, \pi \tau \dot{\omega} \kappa a s, \pi a i \delta \epsilon s, \phi \dot{\omega} \tau \epsilon s, \sigma \tau a \dot{\sigma} \sigma \iota, \lambda \dot{v} \sigma a \iota$, etc., in which the perispasis is suspended. I have indicated above that these cases are in my opinion due to a genuine 'processive' reaction against the recessive tendency, and that Meister is of a different opinion. Whatever their explanation may be-none that is absolutely convincing has to my knowledge been advanced-it must not be forgotten that they rest almost entirely upon reports of native grammarians, and not upon good 'quotable' material. The reported cases of suspended perispasis in trochaic dissyllables are no way fit for testimony against the assumption that this perispasis is Pan-Hellenic, and practically without exception.

That the circumflex here, as in the case of the monosyllabic perispomena, indicates a difference of position, as well as one of quality, we may learn, aside from the general description of the value of the circumflex given above, from a single example of the type $=u$, namely oiko 'houses,' if we compare it with otko 'at home.' It has been known for a long time that the syllable -кo of oiko counted for one mora and that the accent was therefore driven forward to the first mora of oi- (i. e. oiko = oikou), while in otkot the second syllable counted for two moras, and the summit tone was therefore placed upon the second mora of oi- (i. e. oikot = òíxol). Misteli, Ueber griechische Betonung, p. I28, came very near to an explanation of this difference in his sentence: 'Wenn

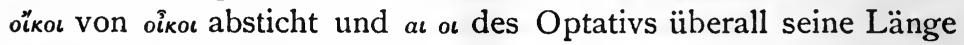
wahrt, so ist im ersten Falle ، eigentlich Casussuffix des Locativs, das mit dem Stammvocale o regelrecht zusammengezogen wurde, und die Folge davon ist eben die Länge, während im Nomin. Plur. jedenfalls die Rede nicht von Zusammenziehung sein kann, so wenig als beim altindischen Pronominalausgang z. B. $t e^{\prime}=\tau o i, y e^{\prime}$ = oi u. s. w.'

Leskien, in the article quoted above, broke the way toward a full explanation of this extraordinary difference by showing that

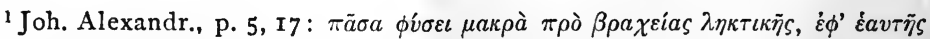

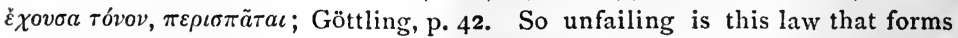
which really ought to have an etymological accent upon the second mora of the first syllable are absorbed by the type $\simeq \cup$. So $\delta o \tilde{v} v a \iota={ }^{*} \delta \circ F_{\varepsilon} v a \iota=$ Vedic

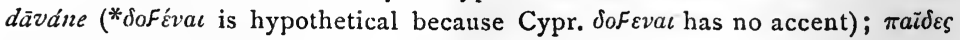
for $\pi a F_{i} \delta \varepsilon S$ acc. to Meister, Zur Gr. Dial., p. 2, cf. above, p. Ir, etc. 
the Lithuanian exhibited two kinds of syllable-tone (in distinction from word-tone): 'cut' tone ('gestossener' accent) and 'drawled' tone ('geschliffener' accent); cf. the footnote on p. 17. Syllables which have the summit tone, as well as syllables without the summit tone (grave syllables), exhibit this difference in the different treatment of the vowels. Hanssen in KZ. XXVII 6I2 fg. successfully applied Leskien's discovery to Greek. According to this theory, o $o$ in a final grave syllable is long if the same syllable with the summit tone has the circumflex; on the other hand, if the same syllable with the summit tone has the acute, then it has the value of a short syllable. If we compare the two nominatives plural oiko and $k a \lambda$ oi with the two locatives singular oiko and 'I $\sigma \theta \mu o \hat{\text {, }}$, we can see that the syllable or of oikor is counted short because it would have the acute when accented (cf. $\kappa a \lambda o i$ ), while the ot of oiko is counted long, because it would be circumflexed if it were accented (cf. ' $I \sigma \theta \mu o \hat{\imath}$ ). We may say that the second syllable of oikot has the 'sub-acute' accent, or 'sub-cut' tone, while the second syllable of oiko has the 'subcircumflex' or 'sub-drawled' tone. Cf. also Brugmann, Grundriss I, pp. 533,539 .

Nothing could show more directly the fact that the circumflex of oiko really represents an acute on the first mora oiko $=$ oikoเ, the acute of oik independently in the case of the long monosyllables is repeated here from a new point of view for trochaic dissyllables; the circumflex of these represents a summit accentuation of the first mora. We must therefore pronounce as incorrect the following of Wheeler's comparisons (p. $20 \mathrm{fg}$.) as far as the accent is concerned: $\eta_{0 s}=$

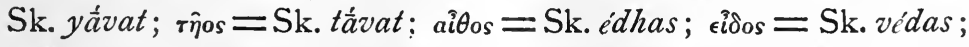

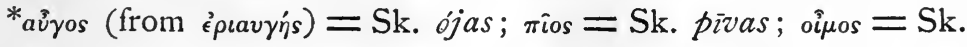

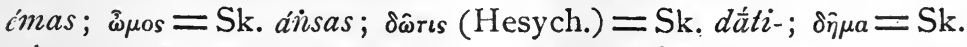

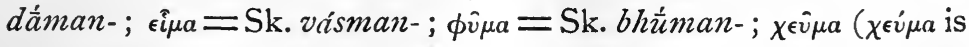
misprinted) $=\mathrm{Sk}$. hóman-; oì $=\mathrm{Sk}$. éman-; $\chi \epsilon \hat{\epsilon} \mu a:$ Sk. adverbial locative héman; ởं ap: Sk. údhar, etc.

One may be fairly surprised that Wheeler discriminated against these forms and shut them out from his theory of a secondary accent. They could have been well enough provided for under its shelter. He allows the secondary accent in iambic dissyllables (three moras): why should it not also have developed upon trochaic dissyllables (of the same number of moras)? On p. I6 he says:

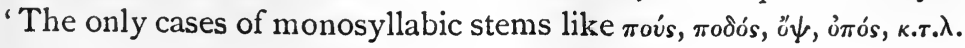
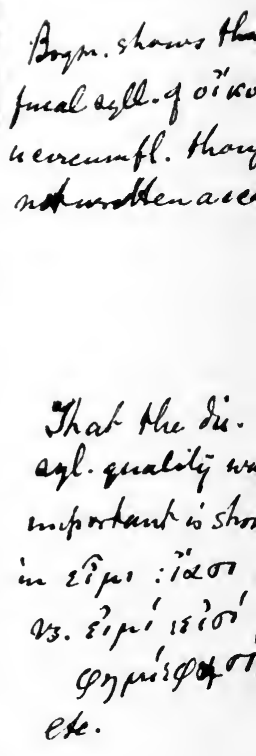
which were fit to receive the subsidiary tone were the genitives and datives plur., and it is worthy of note that the accentual exceptions which are almost unanimously reported by the grammarians appeared in just these cases ( $\pi a i \delta \omega \nu$, etc.).' It seems unlikely that he, whose methods are most rigorous, should have allowed himself to override such considerations, because the assumption of recessively accented trochaic dissyllables would introduce exceptions into almost all his categories of dissyllabic words, and thus prevent the clean-cut arrangement of the words under his category I. Was he prevented from making the assumption of a secondary accent by the unlikely result: a principal and a secondary accent upon the same syllable, $\phi \hat{v} \mu a$, i. e. $\phi \hat{v} \tilde{v} \mu a$ with a secondary accent developed upon the first $\check{v}$ (cf. above)? His attitude here again seems to me, however, best described by saying that he has not regarded the difference between circumflex and acute as an expression of topical difference any more here than above in the case of long monosyllables.

We may, I think, take this for granted from the way in which he explains certain points in the recessive accentuation of the Aeolic (Lesbian).

It has long been customary to regard the Aeolic accentuation as an extreme carrying out of the recessive tendency, without reference to the number of moras involved in a given word. Excepting a few uninflected, therefore solitary words, the prepositions and

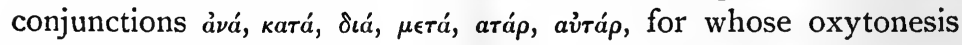
there is good grammatical authority-they have the secondary proclitic accent-the whole mass of word-material has assumed the recessive accentuation, exactly as it holds in the Pan-Hellenic personal forms of the verb. Wheeler, p. 24, attempts to show that his theory of a middle tone needs to be applied also when one is face to face with the over-emphatic application of the recessive principle in the Aeolic. The Aeolic declension of Attic $\theta \bar{v} \mu$ ós is $\theta \bar{v} \mu o s, \theta \dot{v} \mu \omega$ ( $\left.\theta^{\prime} \dot{v} \mu o เ o\right), \theta \bar{v} \mu \omega, \theta \hat{v} \mu o \nu, \theta \bar{v} \mu \epsilon$. He is not willing to recognize independent recession in every case, but applies his theory rigorously. Accordingly it is possible that the genitive and dative should have changed their accent, because the former contained three syllables and the latter is spondaic: there was room for the secondary accent. On the other hand, $\theta \dot{v} \mu o s$ and $\theta \hat{v} \mu o \nu$ must have obtained their accent analogically from such forms as $\theta_{v}^{t} \mu \omega(!)$. But if the process is simply analogical, why not $\theta_{v}^{t} \mu$ s and $\theta^{\prime} \mu_{o \nu}$ ? When Meister, Zur griechischen Dialektologie, makes 
the assumption that Doric $\pi \tau \dot{\omega} \kappa \epsilon s$, yvvaikes, etc., owe their acute to the analogy of $\pi \tau \dot{\omega} \xi$, $\gamma v v \dot{\eta}$, etc., the assumption of analogy, whether made correctly or not, is a reasonable one. But if $\theta^{z} \mu \omega$ shall affect forms like $\theta \bar{v} \mu$ ós, $\theta \bar{v} \mu o^{\prime}$ by 'blind analogy', why the change to the circumflex? Thence I conclude that Wheeler did not bear in mind the difference expressed by circumflex when compared with acute: neither the topical difference nor the difference in quality.

Brugmann, who has adopted for his 'Grundriss' Wheeler's theory without expressed reserve, treats the matter corresponding to Wheeler's first thesis in $\$ 676$, I. Do I err in believing that although he adopts this thesis in his statement, he 'hedges' in the choice of his examples? The paragraph in question is as follows: 'Zweisilbige Wörter mit kurzer Endsilbe lagen ausserhalb der Wirksamkeit des Secundäraccentes und hielten im allge-

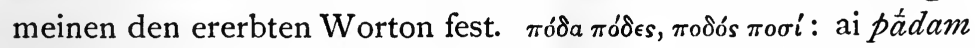

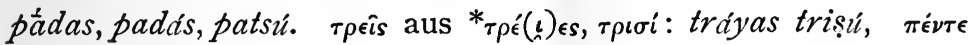

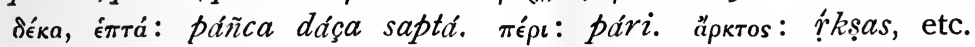

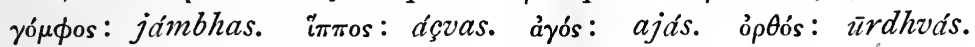

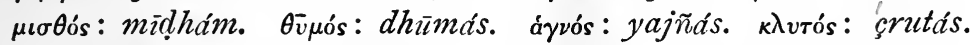

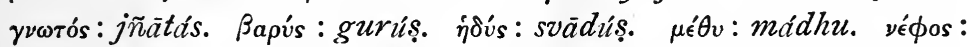

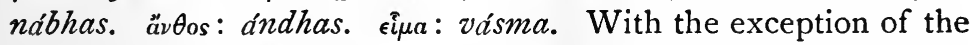
single example eima: va'sma, there is no word with a circumflex mentioned in the passage, and Brugmann may have admitted

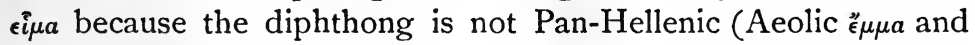
$\gamma^{\prime} \sigma \mu a \tau a={ }^{*} F_{\epsilon \sigma \mu a \tau a}$, Doric $\gamma \hat{\eta} \mu a, \gamma^{\prime} \sigma \tau \rho a . \sigma \tau o \lambda \eta^{\prime}$, Hesych.) It does not seem to me to be without significance that Brugmann has failed to put his signature to accentual equations like $\epsilon^{i} \delta \delta^{\circ}=$ védas, etc., even while adopting the theory which would render them legitimate.

I believe that I have thus far shown that two types of monosyllabic and dissyllabic words do not respond to Wheeler's theory, inasmuch as their explanation from his own point of view demands the assumption of secondary accent under circumstances not provided for by the theory, and under circumstances intrinsically thoroughly improbable. Neither can I give in my adhesion to that part of thesis I which is left after deducting the long monosyllables and the trochaic dissyllables, namely the pyrrhic dissyllables. To begin with, one will naturally be less trustful towards Wheeler's attempt to derive the recessive accent on pyrrhic dissyllables of Aeolic words, by the analogy of forms within the same paradigm, after the fallacy of such a derivation of forms like 
$\theta \hat{u} \mu o s, \theta \hat{u} \mu o \nu$ has been exhibited above. One naturally asks here as several times before: Why this untiring consistency in these cases of 'blind analogy'; why is the tendency always forward, why not sometimes the other way? He explains the change from ropós to oó Nomens dem secundären Accent nicht zugänglich sein mag, werden doch einige der andern Casusformen es immer sein können; z. B.

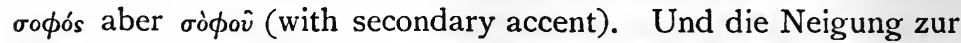
Gleichmässigkeit in der Flexion vermochte dann wohl den einmal in die iambischen oder spondäischen Formen aufgenommenen recessiven Accent durch Analogie auf die trochäischen resp. pyrrhichischen hinüber zu führen. Solches war durchweg der Fall im aeolischen (lesb.) Dialekte.' But we may fairly ask: Why did not the 'Neigung zur Gleichmässigkeit,' if untrammelled by any other tendency, occasionally equalize in the other direction, if the recession of the accent is due simply to paradigmatic analogy, and not to some other cause? Wheeler assumes in the fourth category (his No. V) that a vacillation between the etymological and recessive accentuation took place in the case when the etymological or inherited accent was nearer to the end of the word than the recessive accent. What is it that deprived the Aeolic from the benefit of this choice? Wackernagel, in his review, recognized the improbability of this view, without refuting it: 'Wol aber hätte er die Consequenzen seines Satzes, dass die Tieftonigkeit der aeolischen Mundart unmittelbar mit dem Secundäraccente zusammenhänge, besser erwägen sollen. Der Secundäraccent ist den zweisilbigen Wörtern trochäischer und pyrrhichischer Messung fremd, und doch sind diese im aeolischen ebenso barytonetisch als die andern. Die par Ausnahmen von der Barytonese auf die sich der Verfasser S. 25 beruft (avá, ará $\rho$ u. s. w.) sind lauter Wörter mit dem von ihm auch sonst anerkannten proklitischen Accent auf der Endsilbe.' (Deutsche Literaturzeitung r 886, Nr. 7, Col. 221.)

If the genuine retraction of the accent in Aeolic pyrrhic dissyllables is due to the recessive 'principle,' then the existence of the same in the other dialects is a priori probable, for the Aeolic does not anywhere do more than exaggerate the accentual facts of the sister-dialects. As far as oxytone pyrrhic dissyllables are concerned they do indeed largely retain their accent, but so do all kinds of I. E. oxytones which are not finite verbal forms. That is the one fortress which has never been scaled by the enclitic accentuation: it is ' the last ditch.' But exceptions to the retention 
of this oxytonesis are not wanting in the language any more in the case of the pyrrhic oxytone type $(\cup \dot{v})$ than in the case of trochaic, iambic and spondaic oxytones $\left(-\dot{v}, \cup\left\llcorner\right.\right.$, and $\_\_$), and polysyllabic oxytones. Examples are : vopos 'water-serpent' (Homer) $=$ Sk. udrás 'water-animal'; кózxos 'shell' $=\mathrm{Sk}$. çañkhás ; nólıs $=$

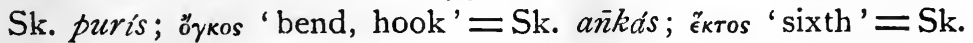
şaștha's; $\pi \epsilon^{\prime} \mu \pi \tau o s=\mathrm{Sk}$. pañçatha's. Much the simplest explanation of the paroxytonesis of $\kappa \dot{k} k \lambda_{o s}$ is to regard it as the recessively

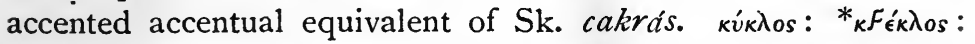
cakrás $=\dot{v} \pi \nu$ os: ${ }^{*}{ }_{\sigma} F_{\epsilon}^{\prime} \pi \nu o s=\mathrm{Sk}$. svápnas, Zend qafuo $=$ Old Norse svefn (orig. Germ. *svéfnos). Kluge KZ. XXVI 100, and Wheeler, p. 23, prefer to derive kík $\lambda$ os direct from the paroxytone German forms, Anglo-Saxon hveohl, Old Norse hvel (for *hvehl); both from a German stem hvéhlo-.

Singular is the explanation which is proposed on p. 33 for the accentuation of abstract nouns in $-\tau \iota s(-\sigma \iota s)$, which are recessive without exception: cf. Historical and Critical Remarks, p. 50 (30). These were originally oxytones, as is shown by their vocalism and the prevailingly reported oxytonesis in Vedic and German. ${ }^{1}$ But in Greek the whole type is completely in the bonds of the 'recessive' accent: $\theta \dot{\epsilon} \sigma \iota s, \rho \dot{v} \sigma \iota s$ and $\dot{\rho} \epsilon \hat{v} \sigma \iota s, \pi \dot{v} \sigma \tau \iota s$ and $\pi \epsilon \hat{\epsilon} \sigma \iota s, \gamma \epsilon \hat{v} \sigma \iota s, \gamma \nu \hat{\omega} \sigma \iota s$,

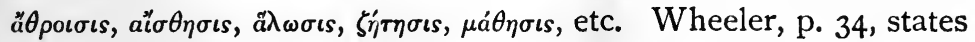
categorically that this accentuation of the type is due to the fact that the abstracts in - $\tau \iota s(-\sigma s)$ compounded with prepositions were originally accented on the preposition: Sk. apaciti 'reverence,' cf.

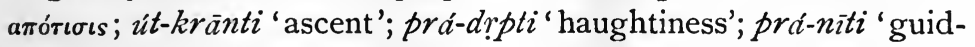
ance,' etc. They therefore had room for the development of the

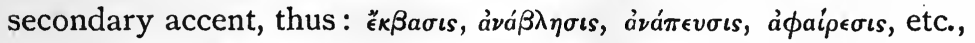
and from these the accent of the uncompounded abstracts was derived by transfer. This explanation is subject to suspicion to begin with, because the parallel formation of the perfect passive participles in -tás (verbals in -rós) when compounded with prepositions also accents the preposition, and yet never makes the least attempt to encroach upon the uncompounded forms. Thus we have Sk. vi-cyuta 'fallen apart': cyutá 'moved, fallen'; a'vanaddha 'bound down '; naddha' 'bound '; prá-vissta ' entered into': vișta' ' entered '; áva-ruddha 'enclosed ': ruddha' 'obstructed,' etc.:

${ }^{1}$ For a few cases in which the accent of abstracts in -ti-s seems to have left the final syllable and passed to the radical syllable in proethnic times, see Bloomfield, Am. Journ. Phil. I 296, and Wheeler, p. 33 (where other references may be found). 
see Bruno Lindner, Altindische Nominalbildung, p. 71 . In the

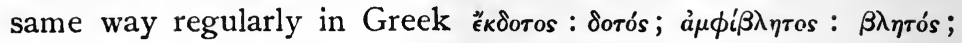

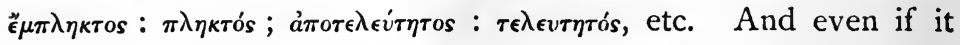
were granted that the absorption of the accent of the uncompounded nouns in - $\tau$ ( $(-\sigma i s)$ by the compounded might have been accomplished, although the old relations in the verbals in tós were left undisturbed ${ }^{1}-$ a freaky choice of analogy-it does not appear clear in what way the accent of ȧmótioıs could have affected the

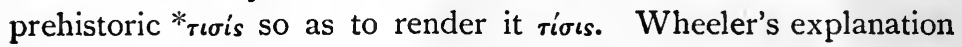
approaches within dangerous proximity of a method which he elsewhere takes especial pains to deprecate. The recessive accent, he says (p. 6), is 'a principle of accentuation, and embraces paroxytones, proparoxytones and properispomena. ${ }^{2}$ It would therefore be necessary that the various accentual types arising in the inflection of arórioıs should have affected severally the corresponding

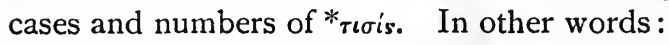

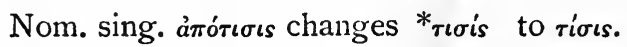

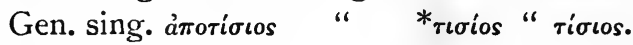

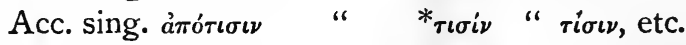

For my part I do not understand in what sense the historical

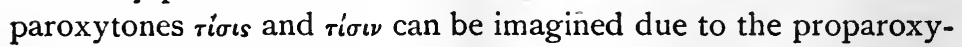

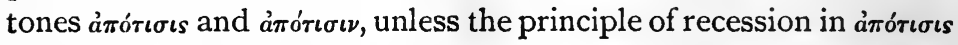
and $a \pi \sigma^{\prime} \iota \sigma \iota \nu$, and that too in the most abstract version imaginable, is supposed to repeat itself in $\tau i \sigma i s$ and $\tau_{i \sigma \nu}$-the very assumption which he contends against. The explanation of the recession in the action-nouns in - $\tau \iota s(-\sigma \iota s)$ is I think as follows: The large mass of abstracts in the language are recessive or barytone: they are not accented upon the ultimate. So the three most prominent types:

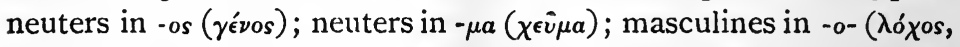
$\phi o ́ p o s)$. The inherited contrast between oxytone nomina agentis and

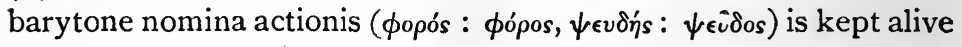

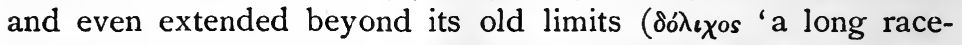

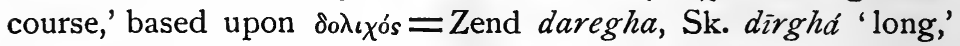

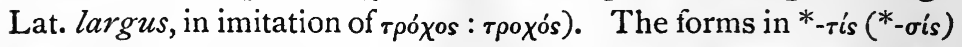
can easily have followed the accentuation of these abstract types,

${ }^{1}$ Nay even there is a vigorous tendency on the part of the accentual type of the uncompounded oxytones to encroach upon the recessive compounds, e. g.

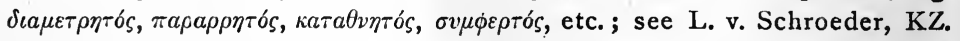
XXIV I22. For the difference in the function of the compounded oxytones and barytones see Göttling p. 313, Kühner I, p. 4I5.

${ }^{2}$ Compare the foot-note on p. 6. 
and if the Greek language really brought with it from the common stock sporadic instances of paroxytones ( $\beta a$ o $\iota s=\mathrm{Sk}$. gátis $=$ Goth. gaquimps; cf. above, p. 29, note), these may have helped on that analogy.

Still more peculiar is the use which Wheeler makes of the unimpaired etymological oxytonesis of several substantival types in order to prove his theory that dissyllabic forms are not recessive. So notably the verbals in - $\tau$ ós. On page 27 we have a list of

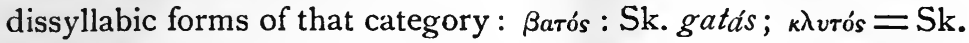
crutás $=\mathrm{OHG}$. hlüt and Anglo-Saxon hlüd, both according to Verner's law from Germanic $h l i \bar{c} ð o ́ s$. But he nowhere tells us upon what ground he makes the undisturbed oxytonesis of these forms dependent upon their dissyllabic and dichronic character. Are there no trisyllabic verbal adjectives in -rós with the same claim to originality as the dissyllabic ones? The types $\tau \iota \mu \bar{a}-\tau o ́ s=$ Lat. amā-tus;

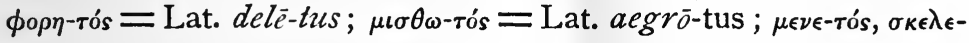

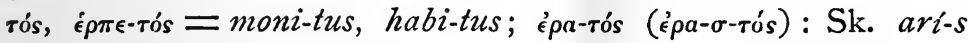

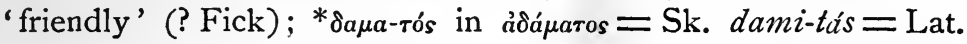

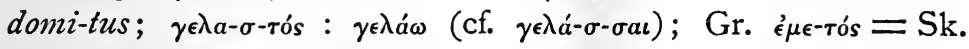

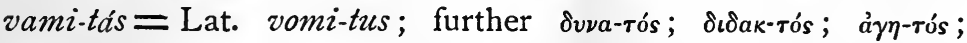

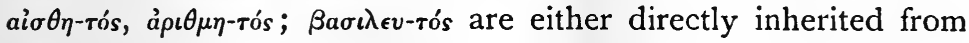
the Indo-European or are more or less modified 'continuators' of I. E. types. ${ }^{1}$ Their numerical representation is probably more extensive than that of the dissyllabic forms. He does not even employ the ordinary domestic remedial expedient-to which we all of us resort for good and for bad-of explaining the undisturbed oxytonesis of the polysyllabic forms as due to the analogy of the dissyllabic forms. He simply mentions, 78 pages later (p. I05), two

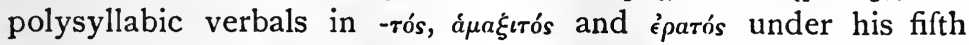
division: 'when the inherited accent lay nearer to the end of the word than the place of the secondary accent a vacillation took place, which was decided in favor of one or the other.' They appear here quite accidentally, as it it were, as representatives of those who chose to retain the old accent. Surely the undisturbed oxytonesis in all uncompounded verbals ${ }^{2}$ is a definite property of the entire category, inherited from the common period, unaffected

1 Cf. now especially Karl Ferdinand Johansson, De Derivatis Verbis Contractis Linguae Graecae (Upsala Universitets Arsskrift, I 886), pp. 96, 97, 100.

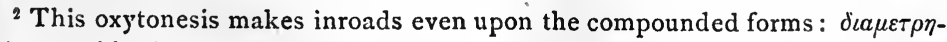
$\tau o ́ s, \pi a \rho a \rho ’ \rho \eta \tau o ́ s, ~ \kappa a \tau a \theta v \eta \tau o ́ s, ~ \sigma v \mu \phi \varepsilon \rho \tau o ́ s$, etc. See Leopold v. Schroeder in KZ. XXIV I22, and note 2 on p. 30. 
by all later vicissitudes of Greek accentuation, whether we call them secondary, enclitic, or recessive accentuation. This oxytonesis is moreover no doubt to be considered along with the oxytonesis of the very numerous active participles, e. g. 'ُ㇒ं $\dot{\omega}=\mathrm{Sk}$.

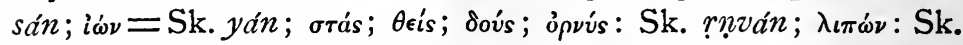
ricán; $\lambda \in \lambda o u \pi \omega ́ s: S k$. ririkvánis-, etc. This brings us to another even more serious manifestation of the same error. Wheeler, in deference to his theory, has divided artificially in his presentation the accentuation of just those oxytone active participles : palpably the most single in origin and treatment. On p. 38 we have the undis-

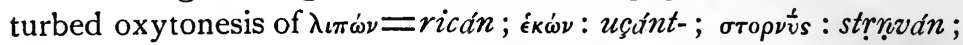
$i \dot{\omega} \nu$ : yant ; $\epsilon^{\prime} \dot{\omega} \nu$ : sán ascribed to their dissyllabic character. ${ }^{1}$ The perfect active participle appears again on page 105 ( $\lambda \epsilon \lambda o \iota \pi \dot{\omega} s, \pi \epsilon \phi \epsilon v-$ $\gamma \dot{\omega} s, \pi \epsilon \phi v \dot{\omega} s$, etc. : Sk. ririkváais, bubhujváàns-, babhüvấns-, etc.), as though there were no link which binds together the accentuation of the dissyllabic and trisyllabic types in their common functional properties. He ought to have been deterred from this error by his own statement (p. 67), that the old middle participles $\delta \epsilon \xi a \mu \epsilon \nu$ '

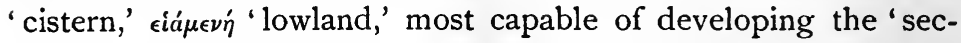
ondary' accent, remain oxytone. All this is of one piece, and in my treatise these facts were presented in peculiarly strong relief: cf. especially Historical and Critical Remarks, p. 50 (30).

For the same reason I cannot grant in any sense that examples based upon the undisturbed oxytonesis of dissyllabic adjectives in -pós prove that dissyllabic forms, as such, preserve the old accentuation. It is true that $\mu a x p o ́ s=$ OHG. magar; $\xi \eta p o ́ s ~ ' d r y '$

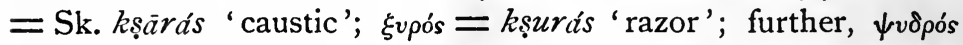
$\lambda_{\imath} \beta \rho$ ós, $\sigma \tau \iota \phi \rho o ́ s, \sigma a ̆ \pi \rho o ́ s$, etc., are oxytone and dissyllabic, but this fact is rendered pointless as far as the theory is concerned by

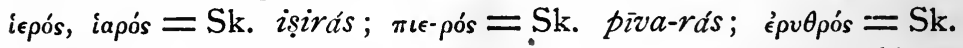

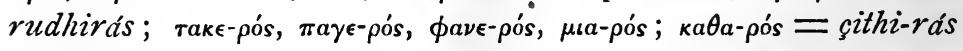

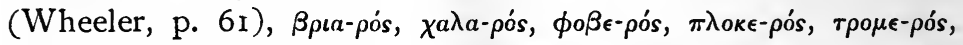
$\pi_{\epsilon} \epsilon \theta_{\epsilon}-\rho o ́ s, \pi o \nu \eta-\rho o ́ s, \mu o \chi \theta \eta-\rho o ́ s, \lambda \iota \gamma v-\rho o ́ s$, and a large number of others; cf. Johansson, loc. cit. p. 97.

Surely any consideration which puts these facts into any other light than that into which the verbals in -rós are put above is mis-

1 The motive by which Wheeler is induced to account in this way for forms like $\lambda \iota \pi \omega^{\prime} \nu, \dot{\varepsilon} \kappa \omega v, \sigma \tau o \rho v v^{\prime} s$ escapes my comprehension. They are iambic forms, and according to his theory are capable of taking the secondary accent. They would belong along with $\lambda \varepsilon \lambda_{0}$ ol $\pi \omega \varsigma, \pi \varepsilon \dot{\phi} \varepsilon v \gamma \omega \varsigma, \pi \varepsilon \phi v \omega \omega^{\prime}$, etc., to his category $\mathrm{V}$, aside from the criticism given above. The same difficulty I find below in the case of the agent-nouns in $-\tau \dot{\eta} \rho,-\mu \dot{\eta} \nu,-\mu \dot{\omega} v$, etc. 
leading. These adjectives have preserved the original oxytonesis as a category, and have-barring singular cases-come in no way under the influence of the 'recessive' accent, whatever this be. I cannot for my part comprehend at all why we find (p. 36) the nomina agentis in - $\tau^{\prime} \rho$ introduced in illustration of the first thesis. All the examples given on this very page go to disprove

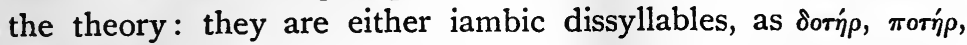
$\theta \epsilon \tau \dot{\rho} \rho, \sigma \tau a \tau \eta \dot{\rho}$, or spondaic dissyllables, as $\delta \omega \tau \eta \dot{\eta} \rho$, $\delta \mu \eta \tau$ ' $\rho$. All these are forms which ought to have the 'secondary' accent, and Wheeler's reason for cataloguing them on p. 36 rather than on p. 105 is obscure in the extreme ( $\delta \mu \eta \tau \eta \dot{\rho}$ occurs in both places). All of these examples, as also $\gamma \in \nu \epsilon \tau \dot{\eta} \rho=S k$. jáni-tar,

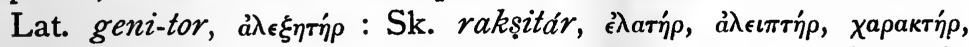

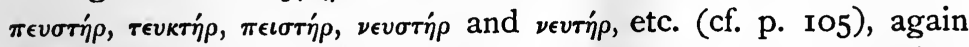
simply exhibit an old oxytone category, left with its inherited accentuation undisturbed by the later vicissitudes of Greek accentuation. All of them ought to have the recessive accent in order to prove anything for the theory of a 'secondary' tone.

I will continue no longer to point out perfectly parallel errors in the rest of the material arrayed in support of the first thesis. Pages 13-38 are in my opinion honeycombed with erroneous presentation: the essential difficulties I have pointed out thus far. It will not prove difficult to apply the same adverse criticism to the use which is made of masculines in $-\mu, \nu$ and $-\mu \dot{\nu}$ on p. $36:$ they are capable of taking the 'secondary' accent, and belong to category $\mathrm{V}$; to the treatment of the adjectives in -ís on p. $3^{2}$ (cf. é $\lambda a \chi^{\prime}$ ís on p. I05); of the nomina agentis in -ós on p. 29 (cf. ảouós, ả $\mu$ oıßós,

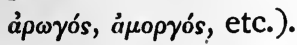

Only one other point needs, I think, especial mention, as it involves a view, held as far as I know, universally and yet methinks incorrectly: It has been the custom up to date in comparative grammar to regard equations like ${ }^{\prime} \lambda^{\prime} \hat{F}_{\text {os }}=\mathrm{Sk}$. çrávas ; ${ }^{\nu} \nu \theta_{o s}=$ Sk. ándhas; $\kappa^{\prime} F_{a s}=\mathrm{Sk}$. krávis ; $\mu^{\prime} \theta v=\mathrm{Sk} . m^{\prime} d h u ; \gamma^{\prime} \boldsymbol{\prime} v s=\mathrm{Sk}$. hánus; r'́ $\rho \mu a=S k$. tárman; $\beta a ́ \sigma \iota s=S k$. gátis $=$ Goth. gaquimps ;

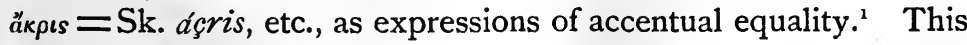
may be regarded as true in so far as the acute on a short syllable

${ }^{1}$ An attempt to cite all the literature in support of this statement would involve references to every author who has considered Greek accent from the day of Bopp's Vergleichendes Accentuationssystem down to our own day. I will therefore merely refer to Bopp's work, especially pp. 25-35; Bloomfield, Historical and Critical Remarks, p. 39 (I9); Wheeler, p. 26 fg.; Brugmann, Grundriss I, \$676, r. 
in historical times in Greek, the udātta on a short syllable in historical times in Sanskrit, and finally the I. E. acute ('cut tone') on a short do not differ from another in quality, barring perhaps such difference as is involved in the question whether they represent chromatic or expiratory accentuation, or a combination of both. It is also true that the summit-tone has never been anywhere else in these types. And yet there is nothing to show that they do not after all really exhibit the recessive accentuation. It must be considered wrong from the point of view of any theory to regard the accent of finite verbal types like $\phi \epsilon^{\prime} \rho \nu$ (I1. 3. 245), an augmentless imperfect $3 \mathrm{~d}$ plur., as preserving in reality the same accentuation as Vedic bharan, I. E. bheron $(t)$, in spite of the perfect

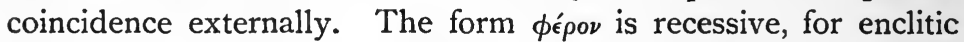
${ }^{*} \phi \epsilon \rho o \nu$; it coincides therefore with Vedic enclitic bharan. This example is typical for every finite verbal form consisting of a paroxytone pyrrhic dissyllable. What right have we to assume that it is otherwise in the corresponding types of the noun? What right have we to regard the 'recessive' accent as suspended in ${ }_{k} \lambda_{\epsilon}^{\prime} F_{o s}$, etc., while finding it in full force in $\psi \epsilon \dot{v} \delta o s, \epsilon i \delta o s, \vec{\epsilon} \rho \epsilon \beta o s$, etc., and in certain cases of the inflection of $\kappa^{\prime} \epsilon^{\prime} \mathcal{F}_{\text {os }}$ itself : ${ }_{k} \lambda_{\epsilon} \mathcal{F}^{\prime}(\sigma) \omega \nu$, etc.? I venture therefore to assert that these types also are in reality recessive. There is in fact nothing but the 'recessive principle' to be found in all dissyllabic word-forms, aside from the retention of proethnic oxytonesis, and some special deflections in every direction, due no doubt every time to singular analogies between word and word, or words and words.

If the preceding exposition is at all correct, then the barrier which Wheeler has erected about dissyllabic word-forms must be considered as broken. To begin with, there is no difference between category $\mathrm{I}$ and $\mathrm{V}$, aside again from special deflections arising from individual analogical effects. I have shown above sufficiently that he pursues an artificial and misleading method when he categorizes dissyllabic forms with the suffixes -rós,

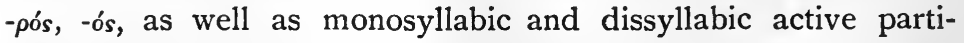
ciples, under thesis I, as not being able to retract their accent on account of their dissyllabic (or monosyllabic) character, while at the same time reporting in a different part of the book that polysyllabic forms of the same categories likewise refuse to retract the accent. I would only add to the details given above that there is no indication in the language that the recessive forms in category $\mathrm{V}$ are even numerically better represented than in category $\mathrm{I}$. 
There is no boundary line of any sort between nominal monosyllables, dissyllables and trisyllables any more than between finite verbal monosyllables, dissyllables and trisyllables: $\beta \underset{a}{b}, \beta \hat{\eta}, \lambda i \pi \epsilon s$, oioa, $\phi^{\prime} \rho \omega, \phi^{\prime} \rho \rho_{\mu \epsilon \nu}, \phi^{\prime} \rho \omega \mu \epsilon \nu$. All these types are repeated in the noun, but they have not become an infallible rule there: they have absorbed some types, while sparing others in a measure.

The third thesis contains material which is absolutely otiose.

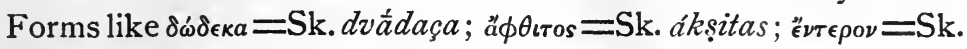

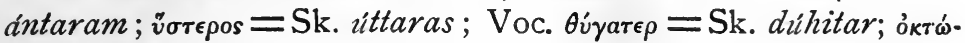

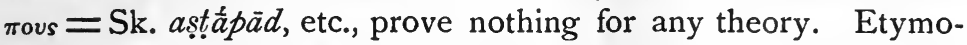
logical accentuation, enclitic accentuation (if that be true), or the assumed secondary accentuation, all meet on neutral ground. I would only add here a statement parallel to that made above (p. 33

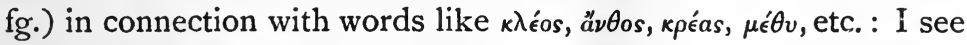
no reason for regarding the accentuation of the type represented by $\delta \dot{\delta} \delta \epsilon \kappa a, \ddot{\epsilon} \nu \tau \epsilon \rho \circ$, etc., as anything else than recessive. The coincidence of the accent with that of I. E. dutodekm, énterom, etc., is

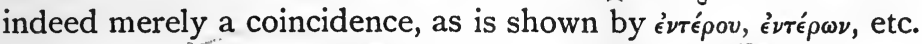

We are thus left with those longer word-forms, in which the etymological accent lay so near the beginning of the word as to leave more than three moras (or four in trochaic polysyllables) unac-

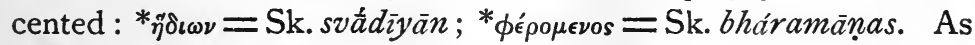
willing as I should be on a priori grounds to admit the effects of a secondary accent in the apparent shift forward of the summittone in $\dot{\delta} \delta i^{\prime} \omega \nu$ and $\phi \epsilon \rho{ }^{\prime} \mu \epsilon \nu$ s, I find myself constrained to judge that there is no more real evidence of its quondam existence in such cases than in any of the preceding, barring of course combinations consisting of an orthotone word plus an enclitic, where the second accent has always been characterized as 'secondary.' In the first place it is to be considered that the terminus a quo from which the count of moras starts in this category is evidently the same as in the preceding categories: the final mora of the word. It seems therefore very unlikely that an essentially different principle was in operation here than in the preceding cases. It would be totally against the spirit of Wheeler's theory to accept this secondary accent as anything else than a phonetic law, pervading the entire material of the language; cf. his remarks on p. 8 and 9, bottom. But we found the assumption of a secondary accent in the types vavis (Aeolic Z $\epsilon \hat{v}$ ) and $\epsilon i \delta o s$ an impossible one: therefore it is also unlikely here. Secondly, the mode of manifestation of the secondary accent in the polysyllabic forms would be an extraordinary one. It strikes

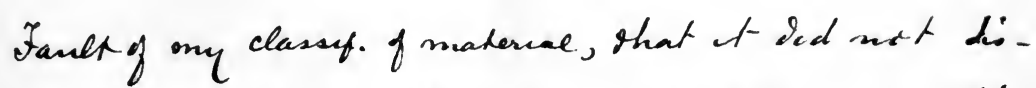

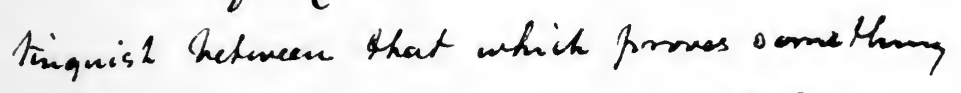
. 
me that a sober definition of a secondary accent means that the utterance starting with the summit tone has a tendency to repetition of the stress or pitch at regular intervals, or bars from the primary accent, and it is difficult to see how the end of the word, already accented, can be introduced as the guide for the deposit of the secondary accent. If the I. E. word bhéromenos $=$ Sk. bháram $\bar{a}$ nas developed a secondary accent upon the second syllable in Greek, so as to produce $\phi \epsilon \rho o ́ \mu \epsilon \nu o s$, we ought to have the secondary accentuation in every case upon the syllable following the primary accent. Instead of this it appears two syllables from the primary

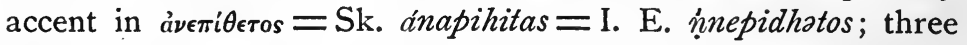
syllables in ả $v \epsilon \pi \imath \theta \dot{\epsilon} \tau o v=\mathrm{Sk}$. ánapihitasya = I. E. ṇnepidhatosio, etc. To put the case still more strongly by bringing an example of an enclitic finite verb, which inclines upon the preceding orthotone word: Is there any likelihood that the phonetic need which did not allow even one unaccented (grave) syllable to intervene between primary and secondary accentuation in * ${ }^{\epsilon} \rho \sigma^{\prime} \mu \in \nu o s=\mathrm{I}$. E. bhéromenos, later $\phi \epsilon \rho o ́ \mu \epsilon \nu o s$, would be content to allow four grave syllables to intervene in I. E. méghisthom bhoreiomedha $=\mu$ '́ $\phi о \rho є o ́ \mu \epsilon a$ ? One asks further: If this accentuation has nothing to do with the history of the word as such (the reverse is assumed if we adopt the theory of enclisis), what right has one to disregard the grave syllables in the word following the one for which the accent is being determined? To illustrate, why are the first two grave syllables of in such a sentence as $\mu \epsilon^{\prime} \gamma \iota \sigma \tau o \nu$ фopєó $\mu \in \theta a$

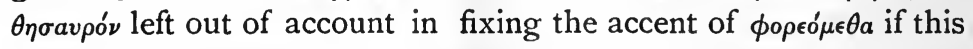
accent is not determined by the character of форєó $\mu \epsilon \theta$ as a word, but by the number of unaccented syllables preceding and following? Wheeler's own words on p. 7 can be brought up against him: 'In der Phonetik des Satzes sind aber die vier letzten Silben in Sk. titikṣāmahãi ebenso sehr enclitisch wie die Verbform in viçvā ékasya vinuidas titikṣate, RV. II I3. 3 ; die zwei letzten Silben in $\phi \epsilon o^{-}$ $\mu \in \theta a$ sowol wie die zwei letzten in dem Lautcomplex ä $\nu \theta \rho \omega-$

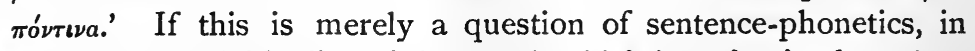
which the individuality of the word, which is maintained particularly by its word accent, is given up, we must consider any group of unaccented syllables in the same light, and the development of the secondary accent on the unaccented syllables of $\mu \dot{\epsilon}^{\prime}(y t \sigma \tau o \nu$

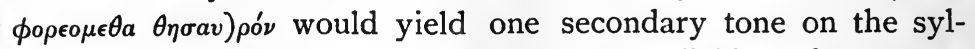

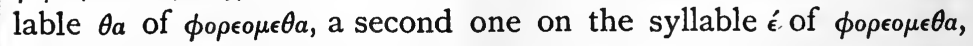

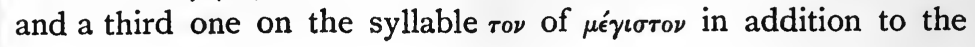


accents actually written. Cf. also the statement on p. II9: 'Die Eintheilung des Satzes in Wörter ist immer mehr oder weniger künstlich. Dieselbe müsste sich in jedem verschiedenen Satz je nach dem Character des betreffenden Wortes und seinen Gebrauch in dem betreffenden Satze verschieden gestalten.'

Further, he who puts the grave syllables in a single word upon the same level as the enclitic syllables in a combination

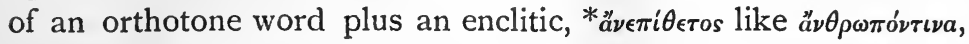
ought to point out some reason why both of the accents in the

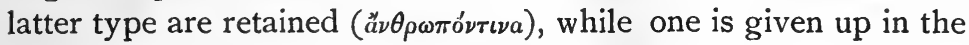

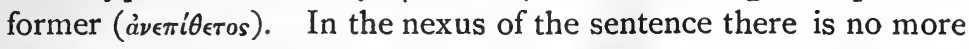
reason for one than the other. And if one were to assume that the first accent of $a ̈ \nu \theta \rho \omega \pi o^{\prime} \tau \tau \nu a$ is due to an analogical restoration after the single word $a \nu \theta \rho \omega \pi \nu \nu$, in other words that the falling aside

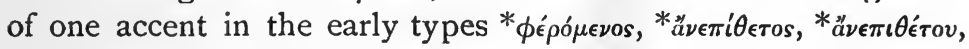
etc., was due to a law according to which a single word could bear but one summit tone, he would still have to point out the reason why the first and original accent always succumbed in the struggle for existence? I do not believe that this could be accounted for without calling in the aid of some external analogy. And that would necessarily be the analogy of the finite forms of the verb. One is absolutely driven to recognize the possibility that the analogy of accentual types is capable of being extended without reference to the function of the words involved. I shall present this view more systematically below, and would submit and emphasize that accentual investigations which exclude this point of view will ever tend to violent and complicated assumptions, such as shall carry their own refutation with them.

I believe that nothing has as yet appeared which is calculated to weaken $m y$ theory that the recessive accentuation in Greek is a modification of a special Greek law of enclisis, which has spread from the finite verb until it has absorbed many quantitative wordtypes in general in the Pan-Hellenic speech and all in the Aeolic. After our renewed survey of the ground, and after having demonstrated the untenableness of Wheeler's theory, the feeling of security in entertaining the theory of enclisis must be enhanced materially. There is as far as can be seen no other $\pi 0 \hat{i} \sigma \tau \hat{\omega}$ for the recessive accent, and I shall endeavor to show below that such objections as have been advanced are either not well taken, or are to be set aside by modifications which do not affect the main current of the theory. I will for the sake of clearness state the theory point for point:
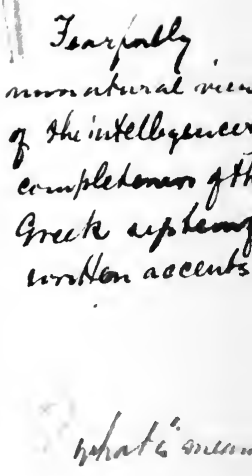
I. The Greek language exhibits distinctly in its treatment of enclitics an aversion against a limitless enclisis. The normal restriction of this enclisis is executed by repeating the summit tone or by supplying with a secondary tone-the difference does not appear in writing - after a certain number of syllables, or rather

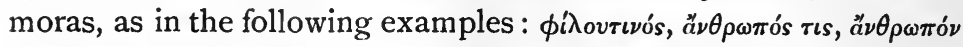
$\tau \iota \nu a, \ddot{a} \nu \theta \rho \omega \pi o_{s} s \phi \sigma \iota$, etc. This secondary accentuation is therefore the syntactical property of a combination of two words, the first of which is accented in such a way that more than the permitted number of unaccented moras would follow. A single word of any number of syllables does not carry more than one accent unless followed by such an enclitic. There is no reason to believe that such a secondary accent develops independently from these syntactical conditions upon any number of grave syllables however great: witness e. g. the interval of five grave syllables in such a

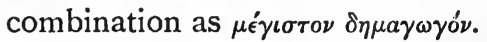

2. The finite verb in principal clauses was enclitic in I. E. times and is so in Greek, when the number of syllables in all the forms of a given paradigm does not exceed the legal number of moras. Such cases are preserved in the inflection of $\epsilon i \mu \iota$ and $\phi \eta \mu \iota$. Elsewhere the enclisis of the finite verb is checked by the excess of moras in the word to be inclined. Wherever some word or words in a given 34 paradigm exceed the number of syllables which are allowed to be inclined, the entire paradigm is orthotone: those forms which have three or more moras take the enclitic tone on the third or fourth mora from the end; when a member of the paradigm does not contain so many moras it places the accent as near to the theoretically correct place as possible, i. e. on the first mora of the

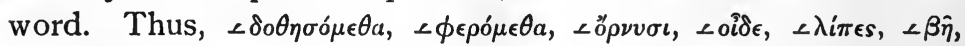

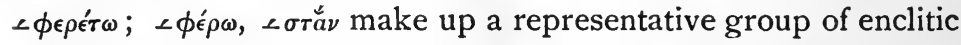
verbal types, some of which are identical with accentual types arising out of a combination of an orthotone word plus a full enclitic,

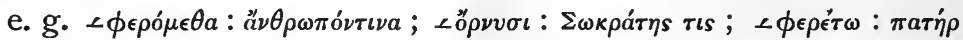
$\mu o v, \stackrel{a}{a} \theta \rho \omega \pi \dot{s} \pi o v$, etc., while others seem not to have any parallel among the ordinary combinations of orthotone word plus a full enclitic. Cf. for this Chandler, $\$ 935$ fg., Wheeler, pp. II 9 fg. ${ }^{1}$

${ }^{1}$ I would not, however, as Wheeler has done, go so far as to deny the originality of all combinations which do not coincide with the verbal law : to assume, e. g., that $\ddot{a} \nu \theta \rho \omega \pi o ́ s ~ \tau \iota s$ and $\ddot{a} \nu \theta \rho \omega \pi \omega \nu \tau \iota \nu \omega \nu$ are combinations in which the position of the secondary accent is regulated by the analogy of $a \nu \theta \rho \omega \pi \sigma v$ $\tau \iota v a$ seems to me very unlikely. Indeed, I consider that the assemblage of 
3. The question as to the manner in which the enclitic accentuation passed from the verb to the noun has been surrounded with unwarrantable difficulties. I do not hesitate to retract my own surmise, that the I. E. enclisis of vocatives and their qualifying words in the middle of a sentence formed the bridge for the transfer of the enclitic accentuation from verb to noun. ${ }^{1}$ We have no enclisis of vocatives reported in Greek at all (no cases of vocative enclisis as in $\epsilon i \mu \iota$ and $\phi \eta \mu \iota)$, and it is perhaps not unlikely that the treatment of the vocative in the middle of a clause became identical with its treatment at the beginning (with I. E. accent on the first mora) before the transition of the enclitic recessive accent from verb to noun took place. So that the vocatives probably were all orthotone before the extension of the verbal enclisis and its substitute, recession, into the noun began. I believe that the transition from verb to noun took place by a kind of analogy, which must be supposed to be largely in operation in the movements of accent. This differs from the kind of analogy ordinarily discussed, in substituting for the two terms form and function the two terms form and accent. I can make my meaning clear very easily. Supposing we have a number of long monosyllables consisting of consonant + long vowel + consonant pronounced with rising-falling inflection $(\Lambda)$, i. e. with circumflex accent. Let us designate this type by $x \tilde{a} y$. Let us suppose that by its side there exists a single instance of a long monosyllable consisting of consonant + long vowel + consonant with falling-rising inflection ( $V$ ), i. e. with cut tone (acute) on the syllable. Let us designate this type by $x a a^{\prime} y$. Will any one be found willing to doubt that this single case, no matter how great its functional distance from the type $x \tilde{a} y$, might be attracted by the latter so as to conform to them in inflection of voice, as well as in number, arrangement and quantity of its consonants and vowels? We may call this-the term is not a new one-analogy of sound or phonic analogy (lautliche analogie). The principle involved in the single example is one without which the rapid permutations of accentuation will never be explained. Wheeler labors strenuously with the doctrine advocated in my essay, that change in accent

cases given on pp. 125-132 teaches rather, that the verbal treatment of enclisis is but one of many other which are possible in the language, so that the law of verbal enclisis is not even binding for all combinations of orthotone plus enclitic, much less for every bit of unaccented territory as in the forms ${ }^{*} \eta^{*} \delta^{\prime} \omega \nu$

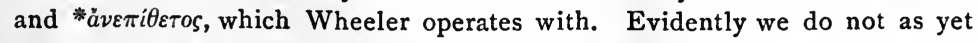
understand all the minutiae of Greek sentence-accentuation.

${ }^{1}$ Cf. Historical and Critical Remarks, 62 (42); Wheeler, p. 7, 49. 
can only be due to regular phonetic change or analogy. But the possibility of this kind of analogy does not seem to suggest itself to him. What straits and improbable assumptions he is led to by operating only with functional analogy we saw best above in his explanation of the completed Aeolic recession. Instead of granting that phonic types equal in the number and arrangement of their consonants, equal in the number arrangement and quantity of their vowels, but differing in their accentuation, would tend to extend the similarity by allowing the accent of the less numerous instances (or for that matter even the more numerous instances) to follow that of the prevailing ones, he prefers the assumption that all the thousandfold instances of recession in the Aeolic, over and above the Pan-Hellenic, were due to assimilation within the paradigm. But he cannot tell us what mysterious force always drove the simple paradigmatic assimilation into the arms of that kind of analogy which wound up with the accent either on the third (fourth) mora from the end, or as near to it as the number of moras contained in the word would allow.

Accordingly I fail to see any other possibility of explaining the

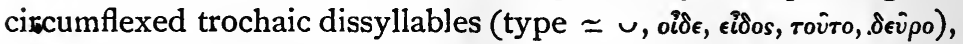
a type which is Pan-Hellenic, without any exception worth remarking; cf. above, p. 24 . If we assume that it belonged originally to finite verbal representatives of the type, due to recession, we have the only explanation with a genuine historical background which has been advanced since the days of the Misteli-Hadley theory. It would be interesting but unessential to see statistics as to the relative frequency of the verbal and non-verbal forms. I do not venture to assert which would turn out more numerous. In the same manner all the various enclitic verbal types of more than three syllables which exhibit the accent upon the antepenult when the

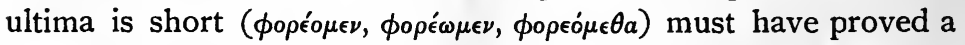
phonetic type of such prevalence and attractiveness that all other accentuation before the antepenult was given up for it. All the various verbal types of more than two syllables, which exhibit the

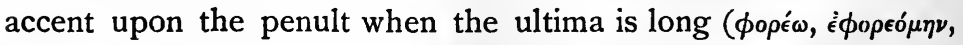
etc.) in the same way attracted to themselves the non-verbal types corresponding. We cannot escape the assumption of purely phonic analogy in this question, and though this kind of transfer seems to call forth our sympathy less readily, though the motive at the bottom of it is less easily apprehended than in the kind of analogy in which form is influenced by similarity of function, it is 
undoubtedly at work in the development of accentual systems. We may add of course that many nouns had the etymological accent upon the same place as the corresponding phonic verbal types, and this may have helped the process of transfer. All the words assembled in Wheeler's third category (p. 56 fg.) are of this sort. This transfer of the enclitic and recessive accentuation to the noun, etc., has been so complete that only a few phonetic types have

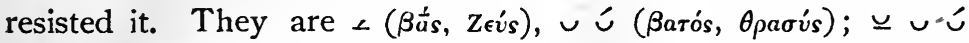

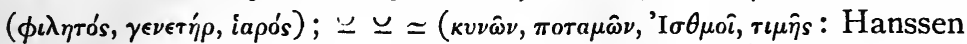

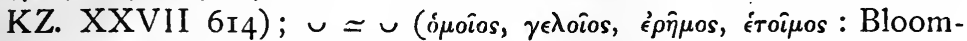
field, p. 4I [2I]; Wheeler, p. I I3). A few old polysyllabic paroxy-

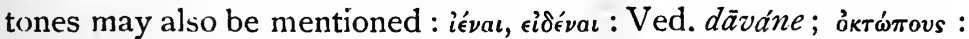

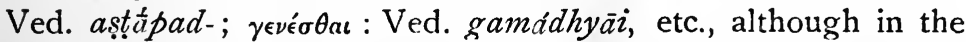
last two cases the paroxytonesis is identical with the 'recessive' accent.

But of these also the majority have made the resistance only in part, and the question as to whether a given form gives up its etymological accentuation is a matter which is usually determined by the category to which it belongs. It is not a question of the number of moras or syllables of which the word consists. It is one of the gravest errors of Wheeler's presentation that he gave to this fact a different coloring. Dissyllabic, trisyllabic, and partly even quadrisyllabic (compounded) verbal adjectives in -rós; adjectives in -pós and -is; monosyllabic, dissyllabic, and trisyllabic active participles ( $\ddot{\omega} \nu, \lambda \iota \pi \dot{\omega} \nu, \pi \epsilon \phi v \dot{\omega} s$ ), etc., are oxytone throughout the language. On the other hand, dissyllabic and trisyllabic nouns in

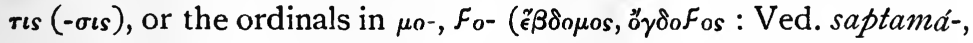
asstamá-), etc., are recessive. The cause of the transfer, while no doubt many times based upon some attraction within the language (cf. the explanation of the recessive accent of the abstracts in - $\tau$ is above, p. 30), is in most cases simply a tribute to the more prevalent accentual types, as $\pi \epsilon \lambda_{\epsilon \kappa v s}=$ Ved. paraçús ; $\pi o^{\prime} \lambda_{\iota s}=$ purís, and many others.

BAltimore, March, $x 888$.

MAURice Bloomfield. 



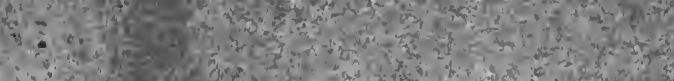

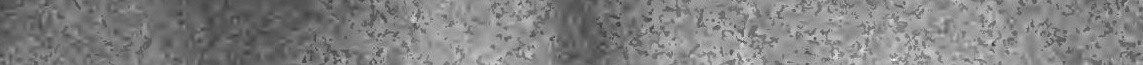

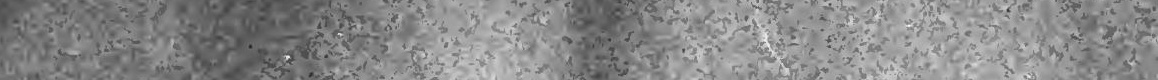
(x) V.

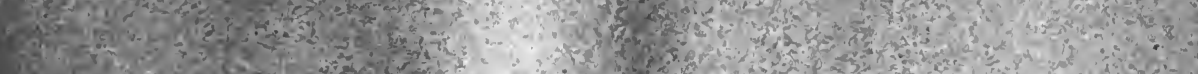

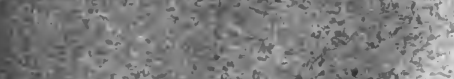
(n)

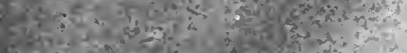

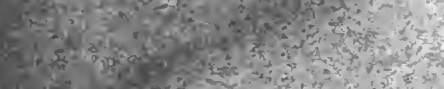

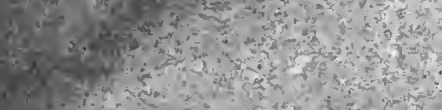
$6, x^{2}$

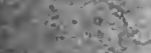
Q3f

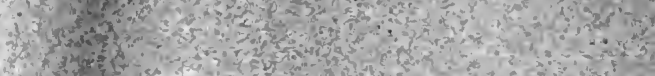

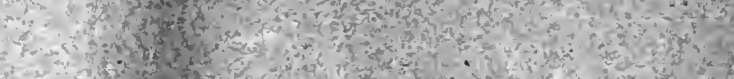
6.

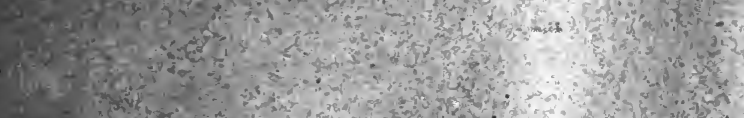
s)

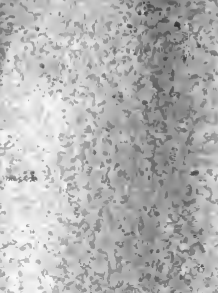
(1)

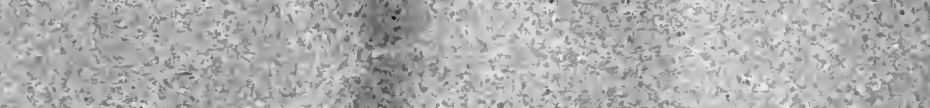
1.

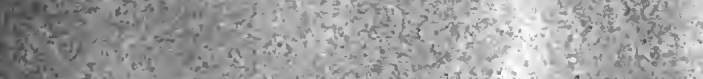

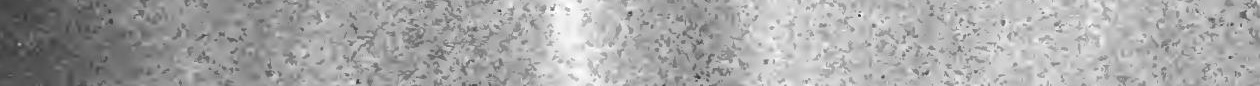

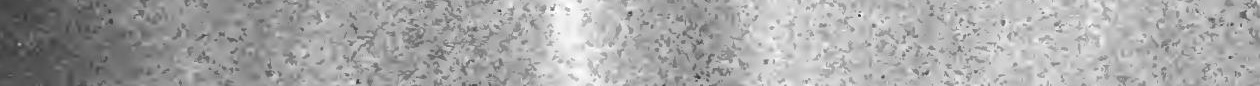
Fin

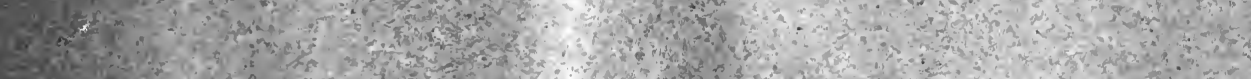

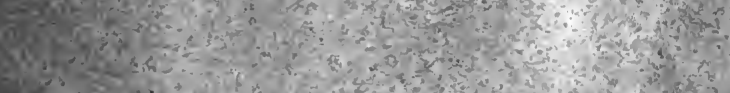

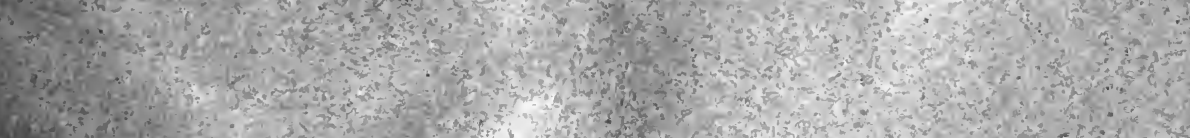
1).

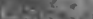

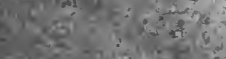
ath

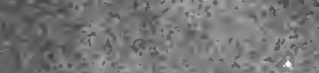

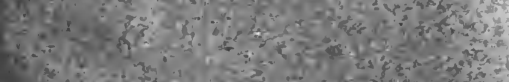

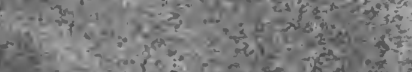

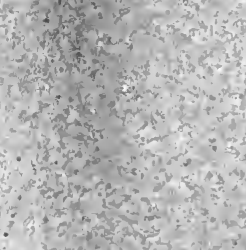
Q

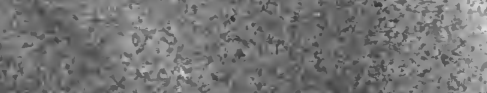

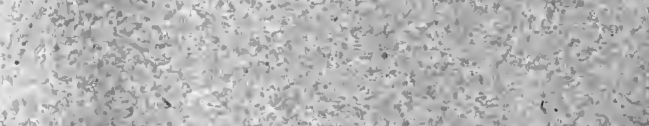

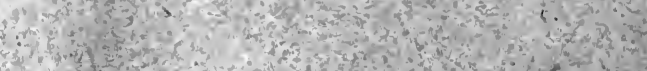

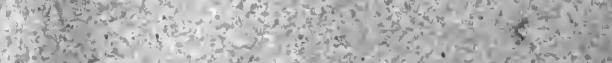

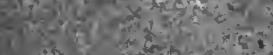

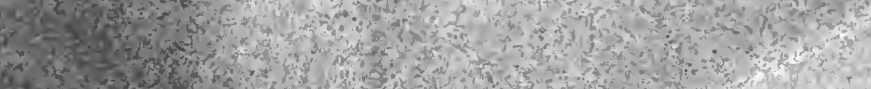

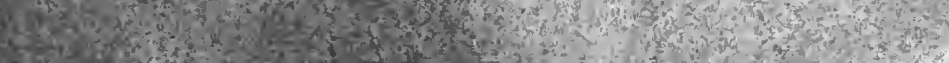



- 


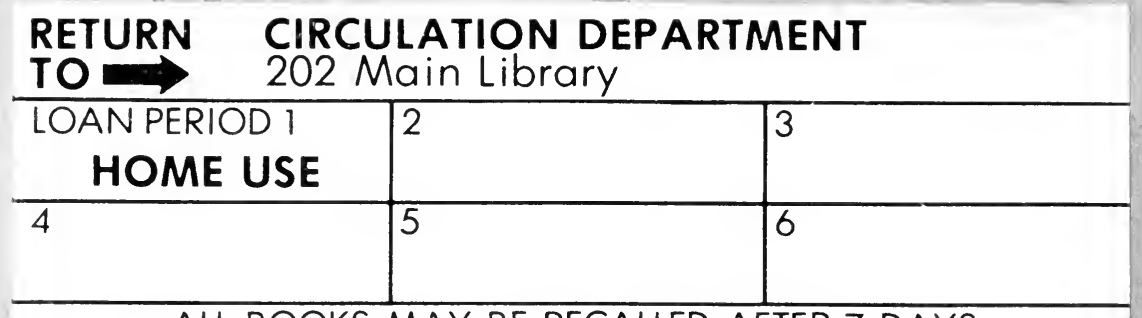

ALL BOOKS MAY BE RECALLED AFTER 7 DAYS

1-month loans may be renewed by calling 642-3405

6-month loans may be recharged by bringing books to Circulation Desk

Renewals and recharges may be made 4 days prior to due date

\section{DUE AS STAMPED BELOW}

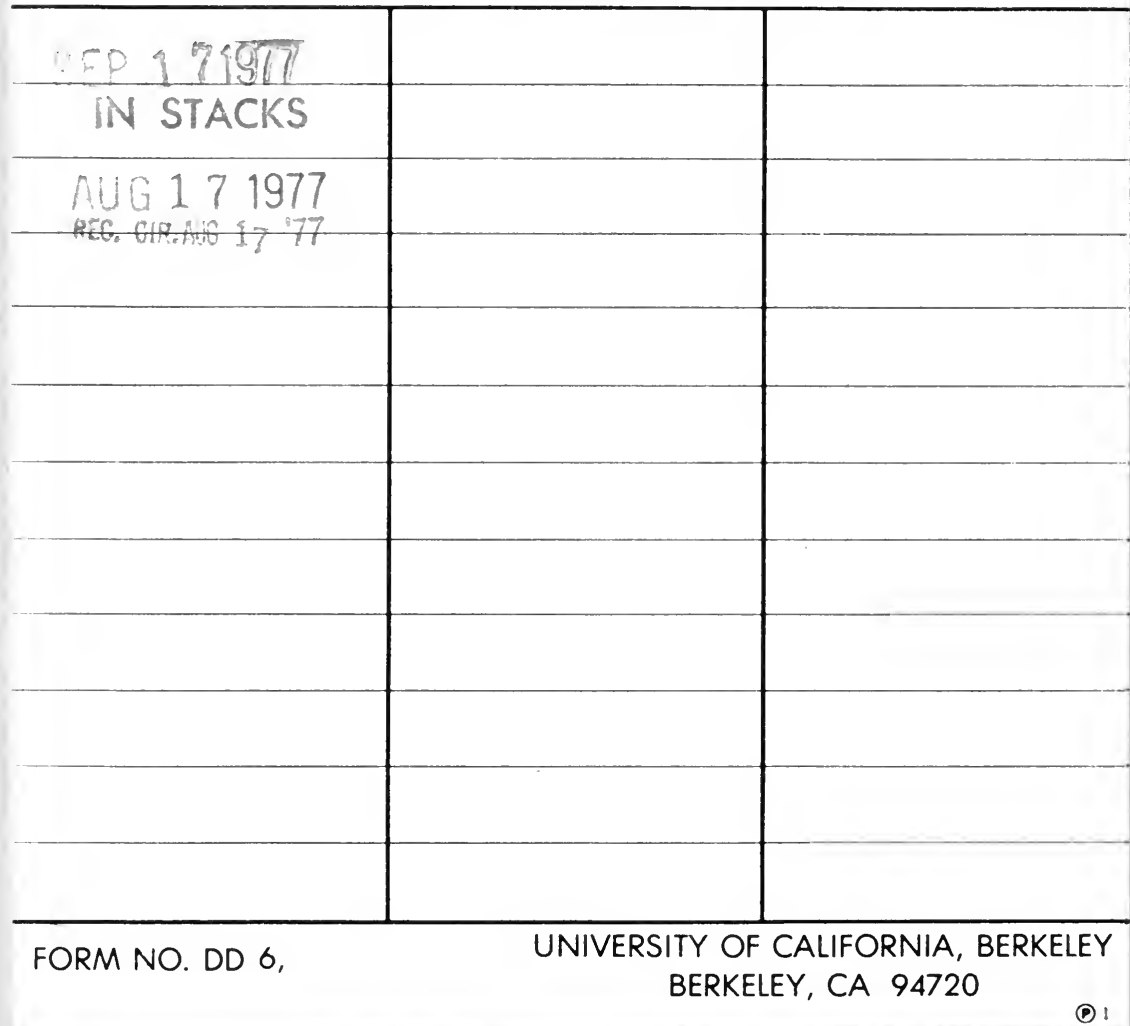




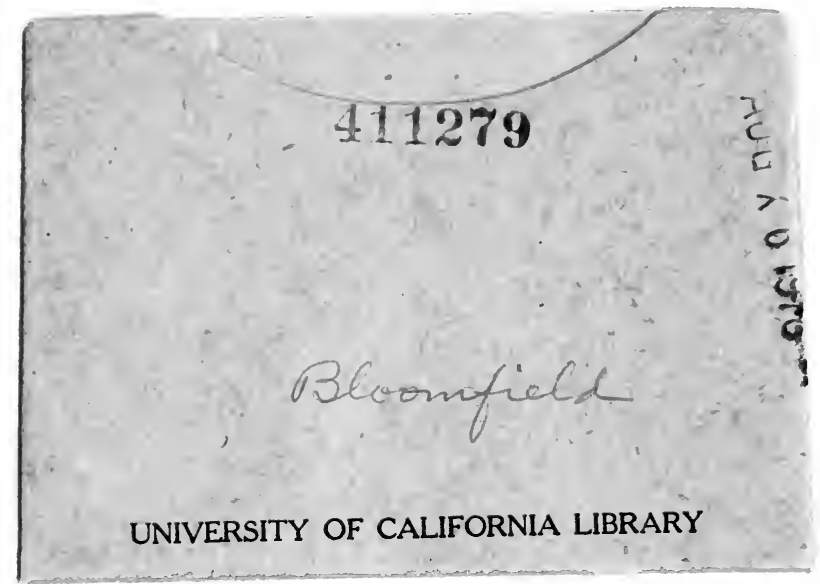


